\title{
Avoiding or Co-Opting ATP Inhibition: Overview of Type III, IV, V, and VI Kinase Inhibitors
}

\author{
Ramon Martinez III, Amy Defnet, and Paul Shapiro
}

\begin{abstract}
As described in the previous chapter, most kinase inhibitors that have been developed for use in the clinic act by blocking ATP binding; however, there is growing interest in identifying compounds that target kinase activities and functions without interfering with the conserved features of the ATP-binding site. This chapter will highlight alternative approaches that exploit unique kinase structural features that are being targeted to identify more selective and potent inhibitors. The figure below, adapted from (Sammons et al., Molecular Carcinogenesis 58:15511570, 2019), provides a graphical description of the various approaches to manipulate kinase activity. In addition to the type I and II inhibitors, type III kinase inhibitors have been identified to target sites adjacent to the ATP-binding site in the catalytic domain. New information on kinase structure and substrate-binding sites has enabled the identification of type IV kinase inhibitor compounds that target regions outside the catalytic domain. The combination of targeting unique allosteric sites outside the catalytic domain with ATP-targeted compounds has yielded a number of novel bivalent type V kinase inhibitors. Finally, emerging interest in the development of irreversible compounds that form selective covalent interactions with key amino acids involved in kinase functions comprise the class of type VI kinase inhibitors.
\end{abstract}

Keywords Allosteric - Docking domains · Protein-protein interactions · Bivalent · Irreversible inhibitors

R. Martinez III · A. Defnet · P. Shapiro $(\bowtie)$

Department of Pharmaceutical Sciences, University of Maryland School of Pharmacy,

Baltimore, MD, USA

e-mail: rmartinez@umaryland.edu; amy.defnet@umaryland.edu; pshapiro@rx.umaryland.edu 


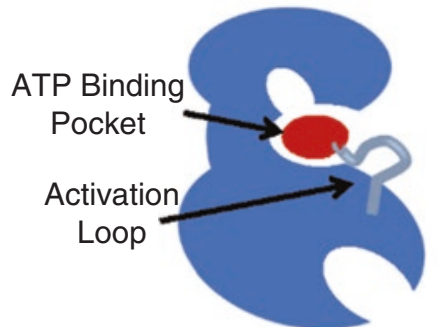

Type I

DFG in (active)

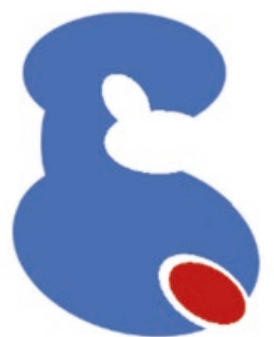

Type IV

Allosteric

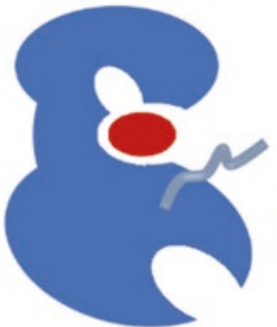

Type II

DFG out (inactive)

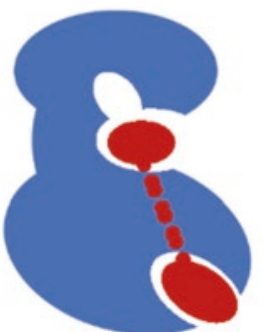

Type V

Bivalent

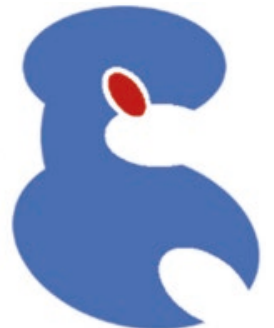

Type III

Allosteric within ATP Binding Pocket

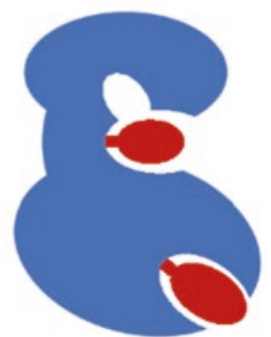

Type VI

Covalent

\section{Part A: Type III Kinase Inhibitors}

The identification of new details about the structural features of kinases, their role in enzyme activity, and their functions in regulating substrate recognition and phosphorylation have prompted research endeavors to develop kinase inhibitors that do not interfere with the highly conserved ATP-binding site. For example, type III kinase inhibitors are compounds that interact with specific structural features in the catalytic site that are adjacent to the ATP-binding pocket. These sorts of innovations are aimed at identifying drugs with reduced promiscuity and associated toxicities as well as avoiding the development of ATP-binding site gatekeeper mutations that are commonly observed to be responsible for acquired resistance to type I and II kinase inhibitors [1].

Type III MEKI/2 inhibitors. The most studied type III kinase inhibitors have been developed against the MAP or ERK Kinase-1/2 (MEK1/2) proteins, which are primary mediators of constitutively active extracellular signal-regulated kinase (ERK1/2) signaling that is observed in many cancers and proliferative disorders. In the early 1990s, researchers, at what was then Parke-Davis \& Company, screened a library of small molecules using an in vitro kinase assay consisting of MEK1, ERK2, and the generic substrate myelin basic protein (MBP) [2]. This screen identified the compound PD98059 to inhibit MEK1 activation of ERK2, to inhibit subsequent phosphorylation of MBP in an in vitro assay, and to block ERK activation 
in cells. PD98059, which turned out to be $\sim 10$ fold more selective for MEK1 than MEK2, was the first non-ATP-competitive inhibitor that paved the way for the development of additional type III MEK1/2 inhibitors. In the early 2000s, the orally bioavailable MEK1/2 inhibitor, PD184352 (CI-1040), was the first type III kinase inhibitor to enter clinical trials [3].

The first structural description of the allosteric-binding pocket on MEK1/2 [4] laid the groundwork for the discovery of additional type III MEK1/2 inhibitors, including selumetinib, cobimetinib, and trametinib that are currently being used to treat several types of cancer. As single agents, the type III MEK1/2 inhibitors have not had the anticipated clinical success [5]. However, the use of the type III MEK1/2 inhibitors in combination with other kinase inhibitors has provided clinical benefits in treating cancer, especially in the context of inhibitors of mutated BRaf where a single amino acid change from a valine to glutamate in the catalytic site causes constitutive activation of the kinase [6]. For example, progression-free survival was greatly improved in melanoma patients receiving cobimetinib (GDC-0973) in combination with the type I BRaf inhibitor vemurafenib to treat mutated BRaf expressing melanoma [7]. Similarly, the MEK1/2 inhibitor trametinib is used in combination with the type I BRaf inhibitor dabrafenib to treat mutant BRaf expressing metastatic melanoma, thyroid cancer, and non-small cell lung cancer [8-10].

The unique structural features adjacent to the ATP-binding site of MEK1/2 have been used to identify compounds that inhibit MEK1/2 activity and may have applications targeting other kinases. Zhao et al. have presented an excellent review of the type III kinase inhibitor-binding mode with a focus on interactions with MEK1/2 proteins [11]. These studies provide evidence that unique structural features in catalytic/kinase domains can be exploited to design more selective kinase inhibitors. The authors compared 29 known structures of MEK1 with type III kinase inhibitors and identified three different allosteric regions in the catalytic site that represent structural targets for inhibitor development (Fig. 1). The first region is a hydrophobic pocket that interacts with hydrophobic groups of inhibitor compounds. The second

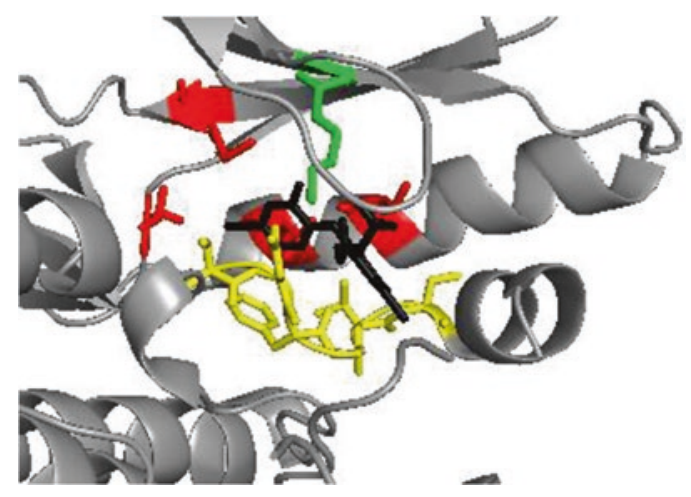

Fig. 1 Structure of MEK1 and allosteric regions near ATP-binding site. Shown is the structure of MEK1 (pdb:1S9J) and three regions, (1) a hydrophobic pocket (L115, L118, V127, and M143) in red, (2) lysine (K97) in green, and (3) residues in the activation loop $\left(\mathrm{C}^{207} \mathrm{DFGVS}^{212}, \mathrm{I} 215, \mathrm{M} 219\right)$ in yellow, involved in allosteric drug binding. The type III inhibitor, PD318088, is shown in black lines 
region is a key lysine involved in enzyme catalysis. The third region includes the DFG motif and parts of the activation loop. The activation loop of the MEK1/2 proteins is unique in that it forms a short helix that allows specific interactions with type III inhibitors [4]. While the activation loop is typically disordered in kinases where structural information is available, other kinases including p38 $\alpha$ MAP kinase and B-Raf kinase, along with MEK1/2, have been reported to adopt these short helix structures in the activation loop [11]. Thus, this unique structural feature could be used to develop type III inhibitors for other kinases. Computational modeling further supports the formation of unique helix structures in the activation loop of other kinases and the potential for selective drug targeting [11].

The structure of cobimetinib bound to MEK1, highlighted in Chap. 2, demonstrates key features that determine the efficacy of type III MEK inhibitors in blocking MEK1/2 in cancers driven by mutations in Ras or BRaf. Previous studies indicate that wild-type and mutant BRaf proteins have differences in their mechanism of MEK1/2 activation [12]. Wild-type BRaf is dependent on the upstream Ras-G proteins whereas mutant BRaf signals through the MEK-ERK pathway in a Ras-independent manner. Based on these differences in BRaf-mediated signaling, the efficacy of MEK1/2 inhibitors in blocking mutant Ras or BRaf cancer cell lines was shown to have qualitative differences [13].

These studies went on to provide evidence that the strength of the type III MEK1/2 inhibitor's interactions with serine 212 (S212, numbering according to MEK1) in the activation loop helix determined the compound's potency in cancers with different ERK pathway driving mutations [13]. For example, the MEK inhibitors that had strong interactions with S212 resulted in stabilized Raf-MEK complexes in the context of wild-type BRaf but not with mutant BRaf. This suggests that the stabilization disrupted the ability of wild-type BRaf to access and phosphorylate MEK in cancer cells expressing mutant Ras. Alternatively, weaker interactions with $\mathrm{S} 212$, as is the case with cobimetinib, were more effective against cancer cells with activating BRaf mutations due to the compound's preferential binding to the activated form of MEK1. The structure of MEK1 with cobimetinib highlights the proximity of the drug with S212 (Fig. 2). These findings provide a novel example where

Fig. 2 Structure of MEK1 and cobimetinib. The strength of MEK1 binding to S212 is implicated in affecting the efficacy of MEK inhibitors in mutant BRaf or Ras-driven cancers. The ribbon structure of MEK1 (pdb:4LMN) is shown in complex with cobimetinib (magenta) and S212 (orange). The conserved catalytic lysine (K97) is in yellow

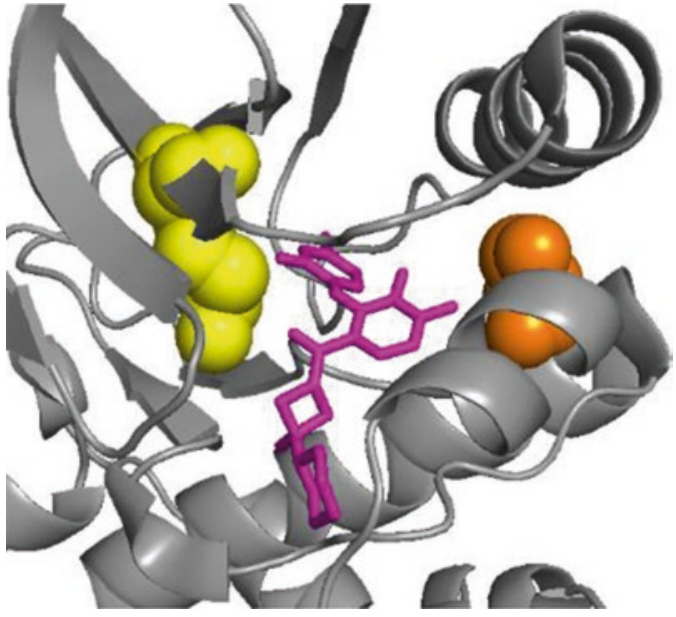


information on kinase regulation, structural features, and chemical synthesis can be combined to design type III inhibitors with optimal efficacy depending on the genetic mutation.

Type III PI3K and Akt inhibitors. Significant effort has gone into identifying compounds that block the phosphoinositide-3-kinase (PI3K) or downstream Akt effector proteins, which are frequently dysregulated and active in many cancer types [14]. Constitutively active PI3K signaling provides cancer cells with survival advantages including inhibiting apoptosis signals and promoting the expression of proteins that promote proliferation $[14,15]$. One of the major targets of Akt in protecting cancer cell survival is the mammalian/mechanistic target of rapamycin (mTOR) protein complex. Although there have been a number of research programs aimed at the development of ATP-competitive inhibitors of PI3K or Akt, compounds identified have shown limited clinical efficacy or cause unacceptable toxicity [14]. Nonetheless, several ATP-competitive PI3K inhibitors are in development and at least three (idelalisib, copanlisib, and alpelisib) have been approved for clinical use in treating types of lymphoma/leukemia and breast cancer [16]. However, as with other ATP-competitive protein kinase inhibitors, acquired drug resistance is a common feature preventing sustained clinical responses.

In addition to type I/II kinase inhibitors, Akt proteins have been the focus of type III kinase inhibitor development. A unique structural feature of Akt proteins is a pleckstrin homology $(\mathrm{PH})$ domain that interacts with the phosphoinositides on the intracellular side of the plasma membrane and regulates Akt activation. Based on the structural differences between a pocket formed by the PH and kinase domains in the inactive versus the active membrane bound Akt protein, a compound called Inhibitor VIII was identified and found to promote Akt1 adoption of an inactive state [17]. The crystal structure reveals key interactions with a tryptophan in the PH domain and residues in the kinase domain that are selective for the Akt1 isoform (Fig. 3). One key finding was the formation of a hydrogen bond between Inhibitor VIII and serine 205, which is not conserved amongst Akt isoforms, and could be used to design Akt1-selective inhibitors [17]. A similar allosteric inhibitor scaffold, referred to as compound Akt-I-1, that was dependent on the PH domain, was also reported to be a selective inhibitor of the Akt1 isoform [18].

Additional type III compounds with similar structures and mechanism of action, in targeting allosteric sites near the $\mathrm{PH}$ and kinase domains of Akt proteins, have entered clinical trials, including MK-2206 [19], BAY1125976 [20], and ARQ 092/ Miransertib [21]. Given the significance of other Akt isoforms (e.g. Akt2 and 3) in mediating mTOR signaling and survival advantages in cancer cells, ARQ 092 was engineered to potently inhibit Akt1, -2 , and -3 proteins. Structural studies between ARQ 092 and Akt1 revealed key interactions with W80 and T82 in the PH domain as well as Y272 and D274 in the kinase domain (Fig. 4). These residues are conserved in all Akt isoforms, which may explain the similar potencies of ARQ 092 against these proteins. Phase 1/2 clinical trials with ARQ 092 was recently reported to show beneficial effects in treating patients with diseases containing constitutively 


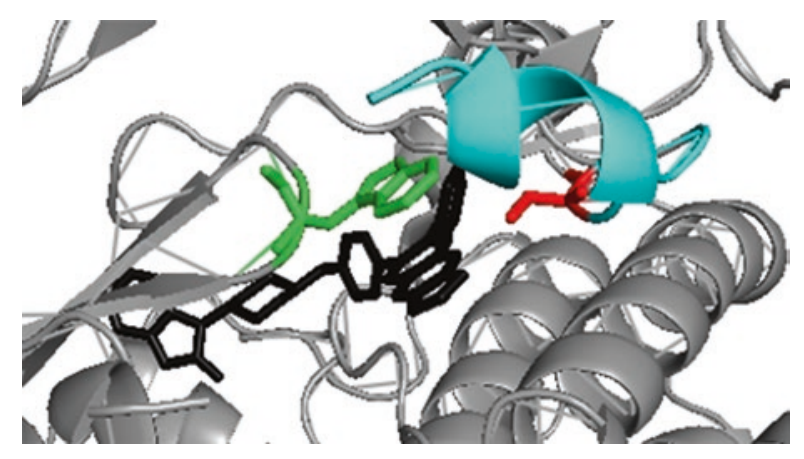

Fig. 3 Interactions between Akt1 and a type III inhibitor. Akt1 (pdb:3O96) is shown in complex with Inhibitor VIII (black lines) interacting with a tryptophan (W80) in the PH domain (red), and residues $189-198$ of the $\alpha \mathrm{C}$-helix in the kinase domain (cyan), and S205 (green)

Fig. 4 Interactions between Akt1 and ARQ 092. Akt1 (pdb:5KCV) is shown in complex with ARQ 092 (black lines) interacting with a tryptophan and threonine (W80, T82) in the PH domain (green) and residues Y272 and D275 in the kinase domain (cyan). Lysine (K97) involved in enzyme catalysis is shown in yellow

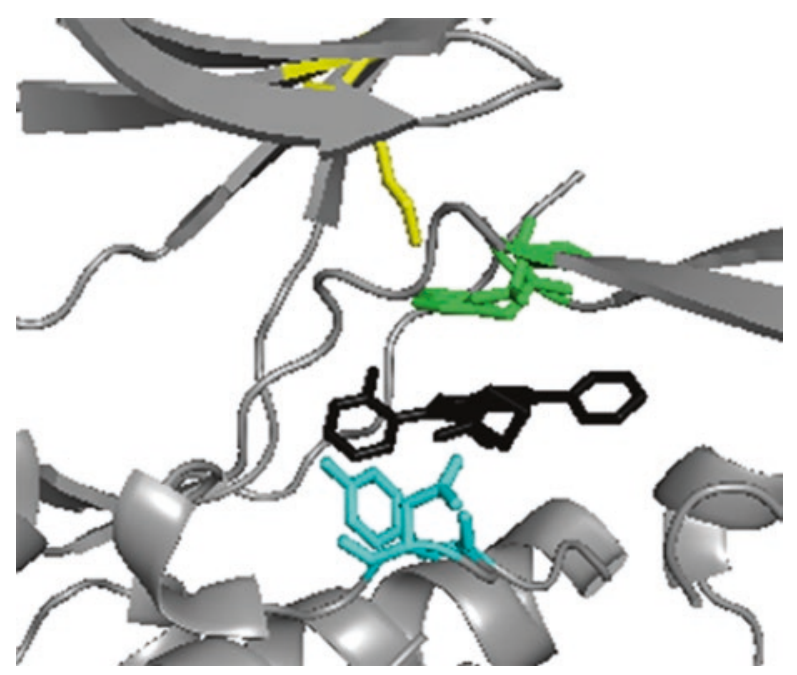

active PI3K or Akt1 including PIK3CA-related overgrowth spectrum, Proteus syndrome, and ovarian carcinoma [22, 23].

Type III Trk inhibitors. The tropomyosin receptor kinase (Trk) family consists of receptor tyrosine kinases that are mostly expressed in neuronal tissue and respond to neurotrophin stimuli to regulate nervous system function [24]. The discovery of elevated Trk activity, as a result overexpression or genetic fusions, in many cancer cell types has promoted the discovery of Trk inhibitors [25]. As a result, a number of broad-spectrum ATP-competitive inhibitors of Trk isoforms, such as FDA-approved 
larotrectinib and others compounds in clinical trials, are showing promising results for treating cancers with high Trk activity [26, 27].

The broad spectrum of functions performed by Trk proteins in regulating neuronal tissue has led to the investigation of isoform specific inhibitors. Of the TrkA/B/C isoforms, TrkA has been the primary isoform implicated to treat pain in mediating pain associated with inflammation [28]. Specifically, TrkA responds to nerve growth factor to maintain the growth and survival of sensory nerves that mediate pain sensation. Thus, TrkA-selective inhibitors are viewed to have clinical potential in treating pain associated with inflammation. However, the current type I and II Trk kinase inhibitors cannot discriminate between Trk isoforms. To overcome this obstacle, Bagal et al. used a cell-based assay to screen for TrkA-selective compounds and identified a type III TrkA kinase inhibitor [29]. Importantly, the compounds showed selectivity for peripheral nociceptor neurons due to enhanced recognition by bloodbrain barrier efflux transporters, which reduced undesirable effects on TrkA signaling in the central nervous system [29]. The key features of the lead TrkA-selective inhibitor, compound 23, reveal interactions with amino acids in a pocket behind the ATP-binding site of TrkA including D668 and R673 (Fig. 5).

The characterization of unique allosteric sites adjacent to the ATP-binding site has promoted the development of selective type III inhibitors that have shown clinical benefits in cancer therapy. Type III kinase inhibitors may help overcome drug resistance to type I/II inhibitors that occurs with mutations in the ATP-binding site of kinases such as EGFR [30]. Additional examples of non-ATP-competitive type III kinase inhibitors have been reported for cyclin-dependent kinase-2 (CDK2) [31] and glycogen synthase kinase-3 $\beta$ (GSK3 $\beta$ ) [32]. It is expected that the future clinical landscape will have more small-molecule protein kinase inhibitors that adopt non-ATP-competitive approaches in their mechanism of action.

Fig. 5 Interactions between TrkA and compound 23. TrkA (pdb:6D20) are shown in complex with compound 23 (magenta lines) making key interactions with residues R673 and D668 (green). The conserved catalytic lysine (K544) near the ATP-binding site is shown in yellow

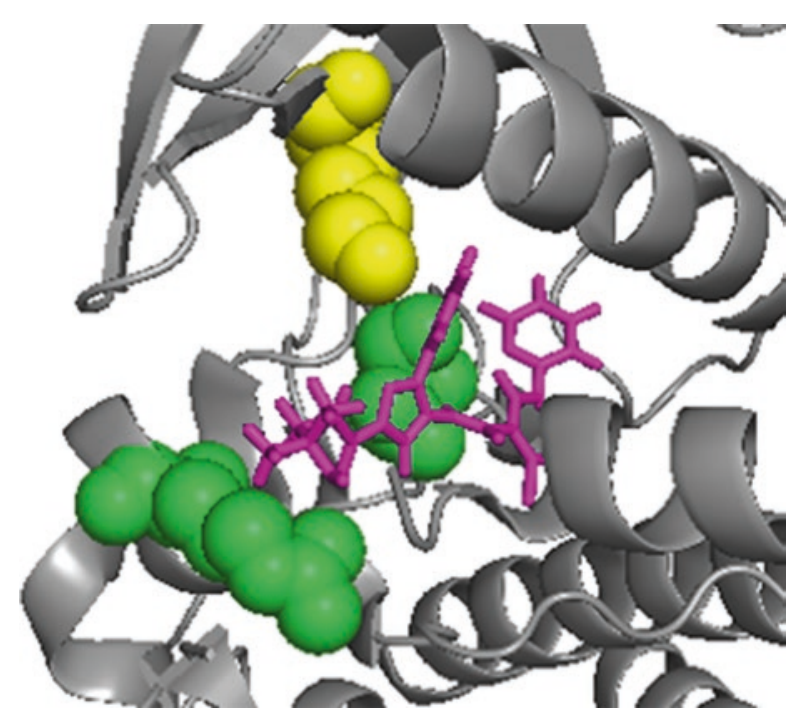




\section{Part B: Type IV Kinase Inhibitors}

A relatively new area in the development of selective kinase inhibitors has focused on targeting unique structural features outside of the ATP-binding or catalytic sites. These allosteric regions are targets of the type IV kinase inhibitor compounds and have the potential to alter enzymatic activity by disrupting the access to upstream activators or prevent the phosphorylation of select downstream substrates. As discussed in Chap. 1, most kinases have pleiotropic functions involving the phosphorylation and regulation of a variety of diverse substrates. Thus, a potential advantage of type IV kinase inhibitors is the opportunity to disrupt the phosphorylation of some but not all substrates. In other words, the type IV kinase inhibitors may enable new approaches to selectively block only the kinase functions associated with a particular disease while preserving other kinase functions that have potential benefits.

A major challenge in targeting allosteric sites outside the ATP binding/catalytic site is determining what sites are important for relevant biological functions. Chapter 4 will present information on studies that have evaluated kinase interactions with regulatory proteins or downstream substrates. This information provides a starting point to identify compounds that could disrupt these interactions. In addition, the Kinase Atlas is a publicly available resource that used FTMap computational resources to help predict potential allosteric kinase hot spots that could be targeted for the development of potential inhibitors or modulators of kinase signaling functions $[33,34]$. The FTMap algorithm examined nearly 5000 kinase structures from 376 different kinases that have been deposited into the Protein Data Bank for predicted binding of small organic molecules. From this, the Kinase Atlas identified ten hot spots outside the ATP-binding/catalytic site that are predicted to contribute to binding free energy of a ligand and are potential drug targets for the development of type IV kinase inhibitors. This section will highlight some recent examples of the discovery of type IV kinase inhibitors and potential applications in modulating kinase functions in disease. $\mathrm{Wu}$ et al. have previously reviewed several allosteric inhibitors that fall into the type III and IV categories [35].

Type IV inhibitors of MAP kinases. New understanding of the binding sites that regulate kinase interactions with substrates has facilitated the development of type IV kinase inhibitors targeting the mitogen-activated protein (MAP) kinases. Focus will be on the three major family members of MAP kinases: ERK, JNK, and p38 MAP kinases. The first studies describing type IV inhibitors of ERK2 were published nearly 15 years ago $[36,37]$. These studies used computational approaches to predict molecular structures that would interact with D-domain recruitment site (DRS)-involved substrate docking to inactive or active ERK2. Several compounds that contained a thiazolidinedione scaffold were shown to reduce ERK-mediated phosphorylation of downstream substrates such as p90 ribosomal S6 kinase (RSK-1) and the transcription factor ELK-1 and inhibited several cancer cell lines in a dosedependent manner [36]. However, the limitations of these studies were the lack of definitive experimental evidence for the binding interactions between the compounds 
and ERK2 and the relative low potency of the compounds. Recent studies [38, 39] highlighting the design of new type IV inhibitors targeting the DRS on ERK2 will be the topic of discussion in Chap. 6.

Additional type IV ERK2 inhibitors have been designed to target ERK2 at the F-recruitment site (FRS), which is involved in regulating the activation of protooncogene transcription factors including members of the Fos family and c-Myc [40]. Bioactive compounds from these studies contained a thienyl benzenesulfonate scaffold and inhibited activator protein-1 (AP1) transcription activity and melanoma cells containing activating mutations in BRaf or NRas. The specific interactions between these compounds and ERK2 have not been experimentally determined.

Dimerization between kinase monomers may affect the activation and subcellular localization of the ERK and JNK MAP kinases [41, 42]. Although dimerization between active ERK2 monomers was initially reported to be essential for nuclear localization [42], other studies provide evidence that active ERK2 dimerization may be related to nonphysiological interactions between histidine tags used for protein purification and that untagged ERK2 exists as a monomer under physiological conditions [43]. Similarly, other studies using fluorescence imaging of live cells indicate that ERK2 dimerization is not required for nuclear entry [44]. However, active ERK2 dimers reportedly function to regulate substrate phosphorylation in the cytoplasm but not in the nucleus [45]. As such, research efforts have examined the potential to inhibit ERK2 dimerization and selectively block kinase functions in subcellular locations. Herrero et al. reported the identification of a small molecule inhibitor of ERK2 dimerization that inhibited cytoplasmic activity of ERK2 and tumor progression in mouse xenograft models [46]. Using in silico modeling, compound DEL-22379 reportedly disrupted ERK2 dimer interactions by forming contacts in a cleft near the activation loop consisting of residues D175, H176, F181, and F329. A nonhelical leucine zipper consisting of residues L333, L336, L344 and ion pairs between H176 and E343 on ERK2 monomers have been shown to be important for the formation of ERK dimers [47].

Type IV inhibitors have also been recently developed to target BRaf dimers [48]. Based on the dimerization interface, cyclized peptides were designed to disrupt BRaf dimers and activation of downstream ERK1/2 pathway signaling. Importantly, this approach may be beneficial in treating cancers with wild-type BRaf and overcome the observed paradoxical activation of ERK1/2 signaling seen with ATPcompetitive BRaf inhibitors [49].

The c-Jun $N$-terminal kinase (JNK) family has been implicated in a number of diseases including diabetes [50]. JNK activity is regulated through interactions with a JNK-interacting protein (JIP1), which acts as a scaffold that facilitates the interactions between JNK and its upstream kinases. Taking advantage of the structural interactions between JIP1 and JNK1, which will be highlighted in Chap. 4, new small molecules that block this interaction and inhibit JNK substrate phosphorylation were identified [51]. These studies used a fluorescence-based assay that screened compounds for their ability to disrupt the interactions between a JIP1 peptide and JNK1. Several compounds were identified to disrupt the JIP1-JNK interactions with $\mathrm{IC}_{50}$ values in the $500 \mathrm{nM}$ range. One compound, BI-78D3, was effective 
at inhibiting JNK activity but was several orders of magnitude less active against related MAP kinases or unrelated kinases. While the exact binding mode of BI-78D3 with JNK1 is not known, these studies provide the basis for generating effective type IV JNK inhibitors.

Additional type IV inhibitors of JNK1 have been identified to target a unique allosteric site that sits below the activation loop [52]. These studies used mass spectrometry to screen $\sim 500,000$ compounds based on their affinity to JNK1. Of the 68 candidate JNK1 ligands identified from the screen, NMR analysis revealed compounds that bound the ATP site or allosteric sites. Figure 6 shows the interactions between JNK1 and an allosteric-binding type IV inhibitor referred to as compound 3 , which contains a biaryl tetrazole scaffold. These compounds are binding to a region that has been shown to regulate interactions with substrates and regulatory proteins [53]. However, there is no evidence that compound 3 modulates kinase function through disruption of interactions with substrates. Modifications of compound 3 yielded non-ATP-competitive compounds that may stabilize JNK1 in a way that interferes with phosphorylation by the upstream MEK7 activator kinase [52].

In addition to small molecules, synthetic peptides targeting the JIP1 site on JNK have entered clinical trials to reduce ocular inflammation [54]. Brimapitide (XG-102) has completed phase II trial with 145 patients, and the effects were reported to be comparable to standard dosing with dexamethasone. Brimapitide is also being tested to reduce JNK-mediated inflammation associated with hearing loss and Alzheimer's disease [55, 56]. A phase III clinical trial at sites in Europe and Asia indicate brimapitide is effective against idiopathic sudden sensorineural hearing loss [57].

The failure of ATP-competitive p38 MAP kinase inhibitors in clinical trials for the treatment of inflammatory disorders [58] has encouraged new approaches to target p38 isoforms including the identification of novel allosteric type IV inhibitors.

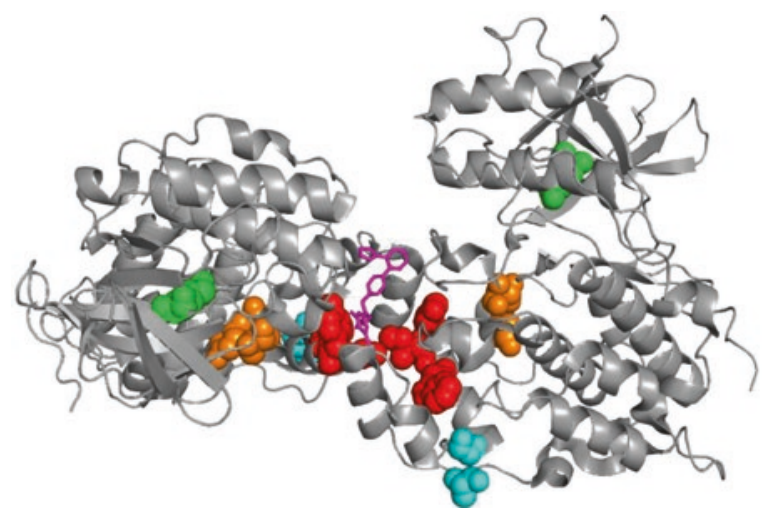

Fig. 6 Interactions between a type IV biaryl tetrazole and JNK1. Shown is a JNK1 dimer (PDB: 3O2M) with activation loop residues T183 and Y185 (red), the MAPK insert sites G242, A267 (cyan), and substrate-docking site residues Y230, I231, W234 (orange) involved in interactions with compound (magenta lines). The conserved K55 involved in ATP catalysis is shown in green 
Like the previous studies identifying allosteric JNK inhibitors, Comess et al. screened for compounds that targeted allosteric sites on p38 $\alpha$ MAP kinase [52]. An allosteric inhibitor, called compound 10, was identified and found to interact with p38 $\alpha$ MAP kinase in a region below the activation loop similar to what was observed with the allosteric compound targeting JNK that was described in Fig. 6. Compound 10 interacted with residues below that activation site that are also adjacent to a substrate-docking site (Fig. 7). Like the JNK inhibitor compound, compound 10 is thought to cause an allosteric structural change that disrupts p38 $\alpha$ MAP kinase activation by upstream kinases.

Shah et al. used computational approaches to identify compounds that target a pocket adjacent to the DRS of $\mathrm{p} 38 \alpha$ MAP kinase [59]. Unique to these compounds were their isoform preference for interactions with $\mathrm{p} 38 \alpha$ over p38 $\beta$ MAP kinase, which may help mitigate excess toxicity observed with the ATP-competitive inhibitors tested previously $[60,61]$. Another potential advantage of these compounds is their ability to inhibit pro-inflammatory substrates involved in acute lung injury associated with acute respiratory distress syndrome (ARDS) but preserve the activation of anti-inflammatory signals that might be beneficial [62]. For example, Shah et al. describe a lead compound, UM101, that inhibited the proinflammatory substrate MAPK-activated protein kinase-2 (MAPKAPK2 or MK2) but preserved the

Fig. 7 Interactions between compound 10 (magenta lines) and $\mathrm{p} 38 \alpha$ MAP kinase. (PDB: $3 \mathrm{NEW})$. Interacting residues $\mathrm{W} 197, \mathrm{~S} 252$, I250, P191, L246, L292 (cyan). Activation site resides T180 and Y182 (green). The conserved catalytic lysine (K53) is shown in yellow

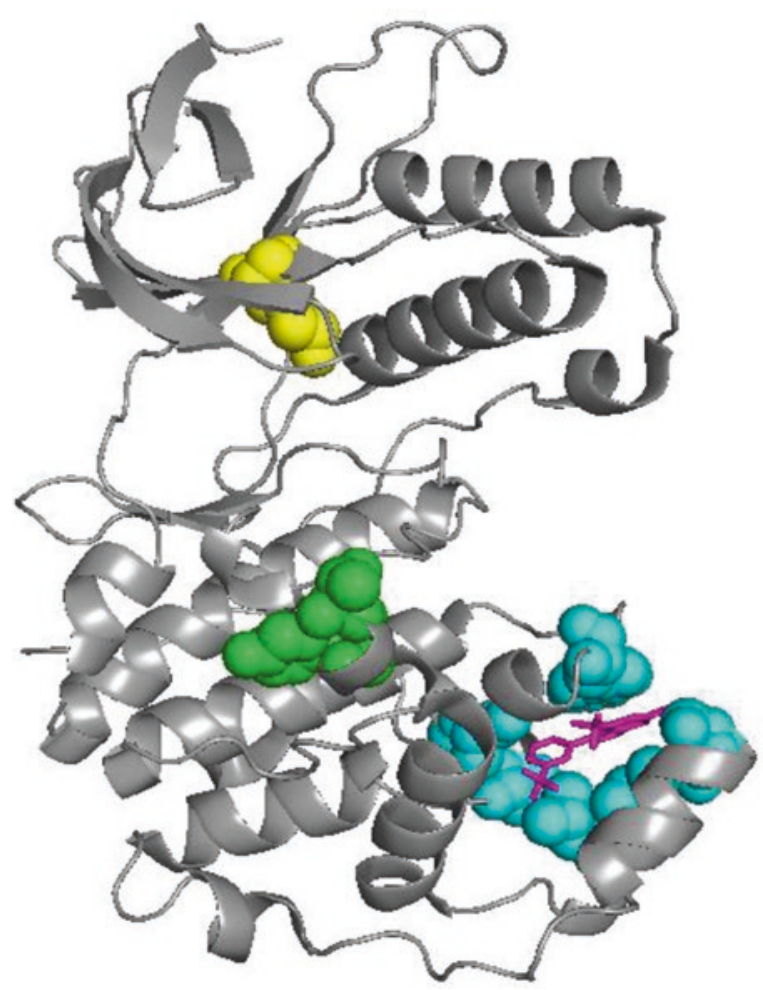


activation of the antiinflammatory p38 substrates mitogen- and stress-activated protein kinase-1/2 (MSK1/2) [59]. The authors went on to demonstrate that UM101 protected against lung damage by reducing endothelial cell damage and neutrophil leakage in a mouse model of lipopolysaccharide (LPS)-induced acute lung injury. These studies provide compelling evidence that function-selective type IV p38 $\alpha$ MAP kinase inhibitors have the potential to reduce toxicity observed with blocking all p38 MAP kinase functions while maintaining in vivo efficacy.

BCR-Abl inhibitors. Efforts to overcome resistance to ATP-competitive inhibitors in the treatment of chronic myelogenous leukemia (CML) have led to the identification of allosteric inhibitors of BCR-Abl [63, 64]. Adrian et al. designed a compound, GNF-2, that targeted the interactions between an N-terminal myristoyl group and a hydrophobic region in the C-terminus of the c-Abl kinase [65]. Myristoylation is a posttranslational modification where a fatty acid derivative of myristic acid is linked to proteins and facilitates localization to cell membranes. It is estimated that $0.5-0.8 \%$ of all eukaryotic proteins are myristoylated [66]. GNF-2 was more effective at inhibiting nonmyristoylated c-Abl than the myristoylated kinase. Similarly, GNF-2 bound to c-Abl and could be competed off with a myristoylated peptide. Furthermore, mutations in the myristoylated-binding pocket of c-Abl blocked GNF-2 inhibitory effects. NMR studies provided further evidence for GNF-2 binding to the myristoylated pocket of c-Abl [63]. GNF-2 was demonstrated to make key interactions with residues in the myristoyl-binding site (Fig. 8).

A.

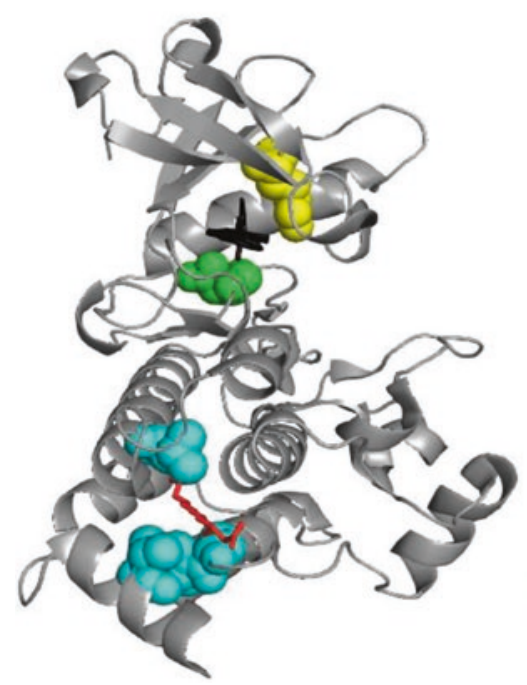

B.

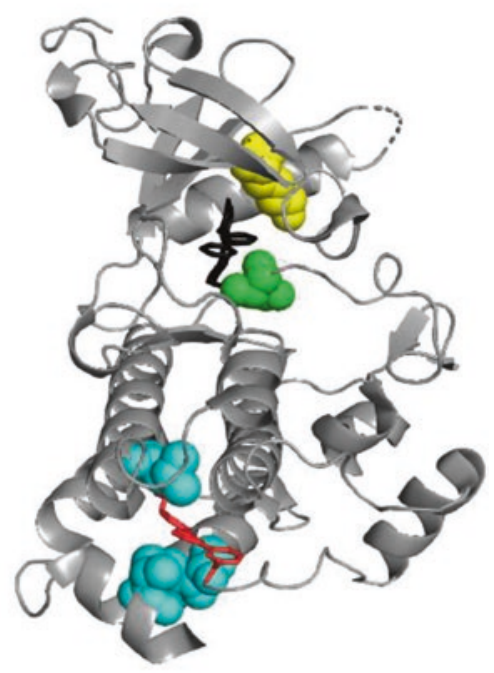

Fig. 8 Type IV inhibition of Abl. (a) Structure of c-Abl with myristoylated peptide (red) and the ATP-competitive inhibitor PD166326 (black lines) (pdb: 1OPK). (b) c-Abl interactions with GNF-2 (red) and the ATP-competitive inhibitor imatinib (black lines) (pdb:3K5V). The conserved catalytic lysine (K271) is in yellow. Myristate-binding site residues L340, D381, C464, P465, V506 are shown in cyan 
Small allosteric compounds targeting the myristoyl-binding site of c-Abl have also been shown to induce conformational changes that activate kinase activity [67]. Yang and colleagues took advantage of structural studies that suggested that interactions between the myristoyl group and the myristoyl-binding site regulated c-Abl activity and identified the kinase activator DPH (5-(1,3-diaryl-1H-pyrazol4-yl)hydantoin). In contrast to GNF-2, which locks a key $\alpha$-helix (see Fig. 8) required for catalytic activity in a closed inhibited state, DPH caused an extension of this $\alpha$-helix observed when c-Abl is activated [67]. While the inhibition of Abl activity is desired in the context of cancers with constitutively active BCR-Abl fusion proteins, activation of wild-type c-Abl may limit breast cancer cell proliferation and metastasis [68].

PDK1 inhibitors. An important co-activator of Akt proteins is phosphoinositidedependent protein kinase-1 (PDK1), which co-localizes with Akt at the plasma membrane through the PH domain. PDK1 is unique because it is required for the full activation of Akt and other members of the AGC protein kinase family [69]. PDK1 interactions with substrates occur through a PDK1 interacting fragment (PIF) pocket [70]. The PIF pocket occupies an allosteric site referred to as helix $\alpha \mathrm{C}$ that regulates protein-protein interactions and kinase activity. Rettenmaier et al. identified small molecules based on a diaryl sulfonamide chemical scaffold that interact with the PIF pocket and inhibit PDK1 [71]. Structural studies revealed key interactions between their compound RS1 and residues R131 and L155 in the PIF pocket (Fig. 9). Although ATP-competitive PDK1 inhibitors had limited efficacy as a monotherapy in mice with acute myeloid leukemia xenografts [72], combining them with the PIF pocket inhibitors may provide greater inhibition of Akt signaling and subsequent tumor suppression [71].
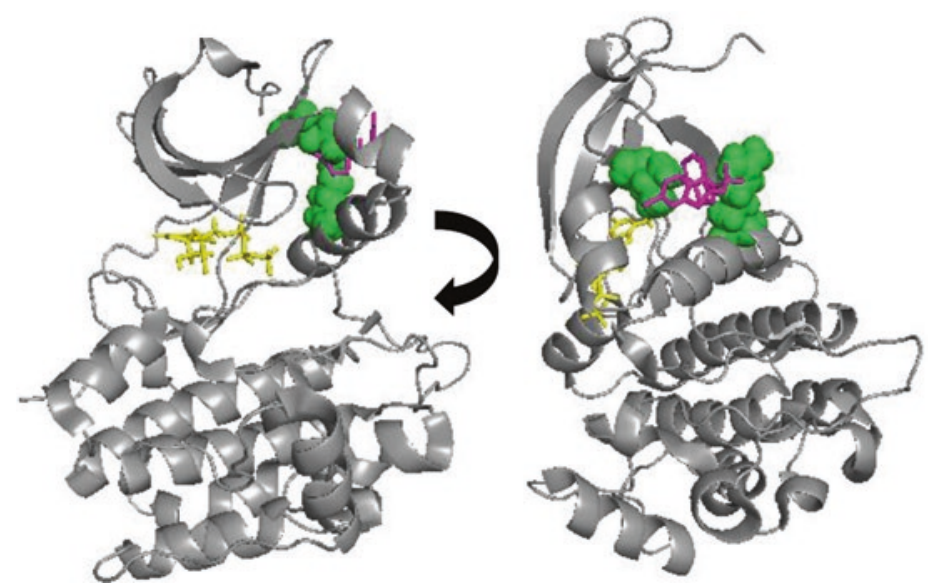

Fig. 9 Interactions between PDK1 and compound RS1. PDK1 (pdb:4RQK) is shown in complex with RS1 (magenta lines) interacting with a R131 and L155 in the PIF pocket (green). ATP is highlighted as yellow lines 
Inhibitors of CDK2 interactions with cyclin A. Allosteric type IV inhibitors have been developed against cyclin-dependent kinase-2 (CDK2) [73]. Cell cycle progression depends on the activity of CDK proteins, which are regulated by association with cyclin proteins. CDK2 activity is essential for progression through G1 and S-phase of the cell cycle and requires association with cyclin A. Based on structural features of CDK2, a type IV inhibitor compound, 8-anilino-1-naphthalene sulfonate (ANS), was identified to bind an allosteric site near the DFG region and causes a structural change that disrupts interactions with cyclin A. The CDK2-ANS structure was shown previously in Chap. 2. However, ANS-binding affinity for CDK2 is relatively low $(37 \mu \mathrm{M})$; therefore, it can be readily displaced by cyclin A [73]. To improve the binding affinity of compounds targeting CDK2 interactions with cyclin A, Rastelli et al. did a virtual screen for compounds that are predicted to interact with CDK2 in the ANS-binding site [31]. Experimental analysis of several lead compounds revealed displacement of ANS from the cyclin A-binding site, which suggested higher potency and targeting to the cyclin A-binding site. Although experimental analysis of structural interactions between these new compounds and CDK2 was not done, these studies provide the basis for targeting the activity of CDK proteins through disruption of interactions with cyclins.

Inhibitors of mTOR. Contrary to compounds that disrupt protein-protein interactions and prevent kinase activation, allosteric compounds that promote proteinprotein interactions and disrupt kinase functions have been well described in the example of the mammalian target of rapamycin (mTOR) kinase. The mTOR kinase complexes (mTORC1 and mTORC2) are critical regulators of the immune system and are upregulated in many cancer cells [74, 75]. Targeted inhibition of mTOR has clinical uses as an immunosuppressant during organ transplants and as anticancer drugs [76]. The natural product rapamycin and related analogues (or rapalogs such as the FDA-approved sirolimus, temsirolimus, and everolimus) indirectly inhibit mTOR by forming a complex with FK506-binding proteins (FKBP). The rapalogFKBP complex associates with a binding domain on mTOR that is outside the active site and involved in facilitating the activation of substrates involved in protein synthesis. In addition to their immunosuppressant roles, the mTOR inhibitors have been FDA approved to treat renal cell carcinoma, breast cancer, and neuroendocrine tumors.

IKK inhibitors. Inflammatory diseases such as arthritis, asthma, and atherosclerosis are thought to be a result of overactivation of the Nuclear Factor kappa-lightchain-enhancer of activated $B$ cells (NFkB) transcription factor [77]. As such, dozens of compounds have been identified to inhibit NFKB activity [78]. To develop more specific inhibitors, efforts to target kinases involved in NFkB activation have

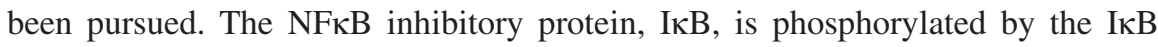
kinase (IKK), which targets IкB for degradation. Loss of IкB allows cytoplasmic $\mathrm{NFKB}$ to translocate into the nucleus and regulate the expression of inflammatory genes. In addition to ATP-competitive inhibitors, allosteric inhibitors of IKK have been identified [78]. Scientists at Bristol-Myers Squibb, using an in vitro kinase assay consisting of IKK isoforms and IкB to screen for compounds that inhibit IкB phosphorylation, identified the IKK inhibitor BMS-345541 that was $~ 10$ fold more 
selective for IKK $\beta$ versus IKK $\alpha$ [79]. Although BMS-345541 does not compete with ATP binding, the exact allosteric-binding mode of this compound is currently unclear. In addition, clinical applications with this or related allosteric inhibitors of IKK have yet to be reported.

\section{Part C: Type V Kinase Inhibitors}

The conserved structure of the ATP-binding site of protein kinases makes it challenging to develop specific inhibitors that block kinases through type I or II mechanisms of action. However, developing compounds that target both the ATP-binding site and a unique structural feature found on a specific protein kinase is the basis for the development of type $\mathrm{V}$ or bivalent inhibitors. With the characterization of binding sites and peptide motifs that determine protein-protein interactions, highly selective and potent type $\mathrm{V}$ inhibitors against tyrosine and serine/threonine kinases have been identified. Gower et al. provided a relatively recent review of type $\mathrm{V}$ bivalent protein kinase inhibitors that have been described [80]. These compounds typically consist of a small molecule that targets the ATP-binding site coupled to a peptide representing the substrate targeted by the specific kinase. This section will describe some of these compounds and the approaches to develop selective type $\mathrm{V}$ protein kinase inhibitors.

Early proof of concept studies for the development of bivalent protein kinase inhibitors used the Src tyrosine kinase as a model [81]. Src and related tyrosine kinases contain an $\mathrm{SH} 2$ domain that recognizes phosphorylated tyrosine and surrounding amino acids on substrate proteins. Xu et al. provided the first structural information of Src describing the coordination between the $\mathrm{SH} 2$ and $\mathrm{SH} 3$ domains involved in protein-protein interactions and the catalytic site regulating kinase activity [82] (Fig. 10). Using this information, a SH2 domain-targeted peptide containing a phosphorylated tyrosine was linked to a nonphosphorylatable peptide that interacts with the Src active site through a $\gamma$-aminobutyric acid linker [81]. The key findings from these studies indicated that the targeting peptides were most potent when linked together and that the number of $\gamma$-aminobutyric acid monomers in the linker was important for maximum Src inhibition. More recent studies linked the SH2 targeting peptide with an ATP-competitive inhibitor to achieve potent bivalent c-Src inhibitors $[83,84]$.

Bivalent kinase inhibitors based on a protein scaffold. Bivalent protein kinase inhibitors as research tools have been developed using the DNA repair protein $O^{6}$ alkylguanine-DNA alkyltransferase (AGT) as a scaffold [85]. AGT contains a cysteine in the active site that reacts with $O^{6}$-benzylguanine (BG). This conveniently allows the coupling of an ATP-competitive inhibitor to AGT through a linkage with BG. Unique AGT fusion proteins can be expressed with a specific peptide ligand that contains the second binding moiety that determines specificity for protein recognition. This technology, referred to as SNAP-tag, provides a convenient approach 
Fig. 10 Structural

domains in c-Src (PDB:2SRC). The SH2 and $\mathrm{SH} 3$ domains are shown in blue and red, respectively. The kinase domain and ATP-binding site are shown in yellow and green, respectively. A potential peptide substrate (magenta lines) interacting with the SH-2 domain and an ATP analog (black lines) are shown

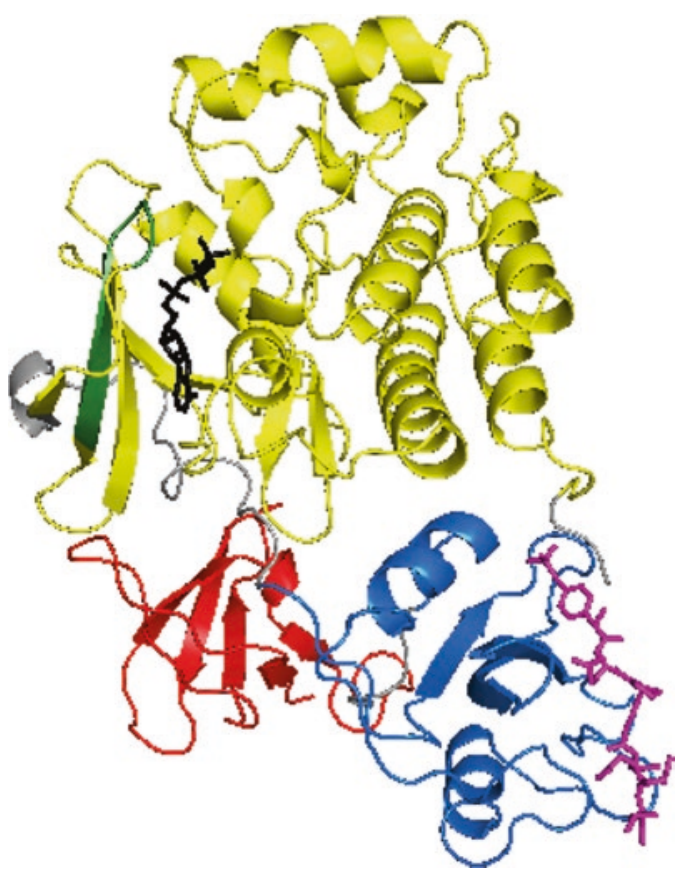

to generate and test the specificity of a variety of ligand targeting sequences and their ability to achieve kinase inhibition in combination with ATP-binding site compounds [86]. Specific AGT fusion proteins containing peptide ligands against Abl1, PIM1, p38 $\alpha$ MAPK, c-Src, and EGFR protein kinases have been described [86-88]. Another advantage of the SNAP-tag approach is that promiscuous ATP-competitive inhibitors can be designed to be quite specific for a particular kinase [89].

Wong et al. described an analysis of three ATP-competitive inhibitors and nine SNAP-tag fusion proteins to determine the contribution of each targeting moiety to the potency of the bivalent inhibitor [90]. These studies indicated that the potency of the bivalent compound was less dependent on the affinity of the specific peptidetargeting ligand but more on the affinity of the ATP-competitive ligand. Nonetheless, even targeting peptides with low affinity can help improve selectivity and potency of bivalent kinase inhibitor compounds [90]. While the utility of these types of bivalent inhibitors will be relegated to research tools for evaluating kinase functions, these approaches provide the basis to design bivalent kinase inhibitors for clinical applications.

Small-molecule peptide bivalent Inhibitors. Several MAP kinases have been the target of bivalent inhibitors. Stebbins et al. identified compound 19 that consisted of an ATP-competitive inhibitor coupled to a short D-domain peptide, which was sufficient to displace the JIP1 protein from the D-recruitment site on JNK1, and a cell penetrating peptide [91]. Compound 19 inhibited JNK1 kinase activity in vitro and in cell-based assays at low $\mathrm{nM}$ and $\mu \mathrm{M}$ concentrations, respectively. This compound also improved glucose tolerance in a mouse model of type 2 diabetes, which 
is a potential clinical application for JNK inhibitors. A similar strategy was used to generate an ERK1/2 selective bivalent inhibitor (SBP3) consisting of an ATPcompetitive inhibitor (FR180204) and a 16-amino-acid peptide corresponding to the D-domain of the ERK1/2 substrate, ribosomal S6 kinase (RSK1) [92]. Combining the targeting moieties into the bivalent compound increased the potency more than 50 times as compared to either the ATP-competitive inhibitor or the D-domain peptide alone. Figure 11 shows the reported structure of SBP3 with active ERK. As shown, SBP3 forms contacts with ERK2 through the RSK1 peptide and FR180204; however, the linker of these targeting agents does not appear to be involved in ERK2 interaction [92]. Despite the intended design for SBP3 to target ERK1/2, this compound also potently interacts with JNK and p38 MAP kinase isoforms.

A study reported the use of a cyclic decapeptide that corresponds to an extracellular region of the epidermal growth factor receptor (EGFR) regions involved in dimerization [93]. Combining two of these peptides together using a polyproline linker created a bivalent ligand that inhibited EGFR autophosphorylation presumably by preventing the two EGFR monomers from dimerizing. Ephrin type-A receptor 3 (EphA3) is another receptor tyrosine kinase targeted by bivalent compounds [94]. These studies highlight the potential of using longer linkers to couple ATPcompetitive inhibitors with small peptides that target unique regions far away from the ATP-binding site. Not only did this approach enhance the potency of a weak

Fig. 11 Structure of bivalent compound SBP3 and ERK2 [PDB: 5V62]. SBP3 shown consisting of a RSK1 peptide (magenta lines) and the ATPcompetitive compound FR180204 (green lines). D-recruitment site residues T158, T159, D316, D319 (cyan). The conserved catalytic residue (K52) is in yellow

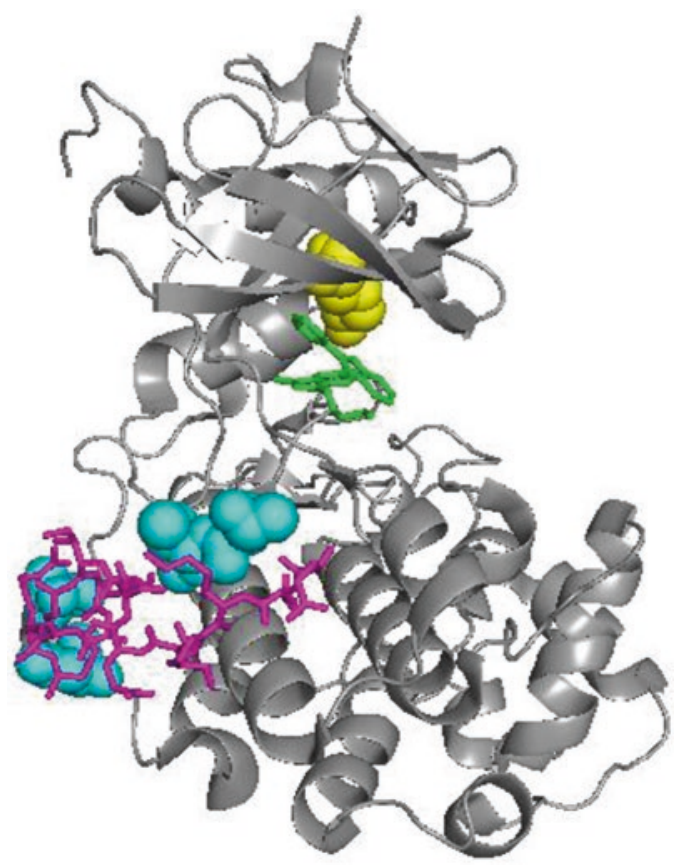


ATP-competitive inhibitor, it supports the advantage of using structural information to design a wide range of bivalent targeting moieties.

The PIM kinases (referring to the proviral insertion site in Moloney murine leukemia virus) are overexpressed in several cancer types and appear to exacerbate proliferative disorders [95]. Bivalent PIM kinase inhibitors have been developed using D-arginine-rich peptides (ARCs) and adenosine analogs [96]. Arginine-rich sequences are found on many substrates recognized by basophilic protein kinases found in the AGC protein kinase group. Even though PIM kinases fall in the calcium-calmodulin-dependent protein kinase (CAMK) group, Ekambaram et al. provided evidence that potent bivalent inhibitors using ARCs can be selective for PIM-1 kinase but not members of the AGC protein kinases [96].

These studies provided evidence that targeting two separate structural features on protein kinases with bivalent compounds could be an effective approach to inhibit the activity of a specific kinase. While many of the approaches to develop bivalent protein kinases inhibitors have yielded useful research tools for understanding signaling pathways and biological mechanisms, the clinical applications of these compounds in treating disease have yet to be realized. The large size of bivalent inhibitors may present barriers to their use in targeting intracellular protein kinases. The potential to design smaller peptidomimetic compounds that target specific substrate interaction sites may overcome drug delivery and bioavailability issues associated with using peptides as targeting moieties or therapeutic agents [97].

\section{Part D: Type VI Kinase Inhibitors}

There has been resurgence in the development of compounds that form covalent, and generally irreversible, interactions with protein kinases to provide sustainable inhibitory effects primarily to treat cancer. The prospect of developing covalent inhibitors faced criticism of extensive off-target effects. However, there is historical precedence for the benefits and potential risks of developing covalent-binding drugs. Probably the best example of the benefits of covalent bond-forming drugs is acetyl salicylic acid or aspirin. Although the beneficial antiinflammatory and analgesic effects of aspirin have been recognized since its discovery in the late 1890s, it was not until the 1970s that its mechanism of action was identified to involve the formation of covalent adducts on cyclooxygenase enzymes and the reduced production of inflammatory cytokines [98]. However, other drugs like acetaminophen metabolize into highly reactive species that form toxic covalent adducts with liver proteins and can cause liver damage at high doses. Despite the understandable concerns about the off-target effects of covalent-binding drugs, advances in structural and computational biology have made it feasible to develop inhibitors that form covalent interactions with protein kinase inhibitors that are selective, efficacious, and have reduced toxicity. This section will highlight some of the features of clinically relevant covalent kinase inhibitors and the potential for expanding the development and use of covalent kinase inhibitors in disease. 
Recent reviews of covalent small-molecule protein kinase inhibitors provide an excellent summary of the compounds identified to target specific kinases [99, 100]. Covalent type VI protein kinase inhibitors utilize chemical features of the noncovalent type I-IV kinase inhibitors that interact with the ATP-binding or other regions near the kinase domain. What makes the type VI protein kinase inhibitors unique is the inclusion of reactive electrophilic groups or warheads that react primarily with nucleophilic cysteines although reactions with lysine, aspartic acid, and tyrosine residues can be used to form covalent interactions. Like other drug discovery approaches, type VI kinase inhibitors use structure-guided design approaches that take advantage of noncovalent interactions with the targeted kinase in order to increase specificity and position the warhead component for targeted covalent interaction that locks the inhibitor in place. The covalent adduct typically forms through a Michael addition reaction, and many of the electrophilic moieties used to develop type VI inhibitors utilize an acrylamide group that favors interactions with cysteine residues. In addition, alterations in the reactivity of the electrophile warhead may be used to create reversible covalent protein kinase inhibitors whose duration of inhibition may need tighter control [101]. For example, most protein kinase inhibitors that are used to treat cancer might be more effective by a sustained mechanism of irreversible inhibition. In contrast, shorter-acting reversible type IV inhibitors might expand the clinical applications and reduce off-target reactivity and toxicity [101, 102].

An early example of type VI covalent protein kinase inhibitors was the discovery of the mechanism of action for the fungal metabolite wortmannin [103]. Wortmannin was identified to be an irreversible inhibitor of PI3K isoforms through the formation of a covalent adduct with a conserved lysine (K802) in the catalytic site [103]. However, wortmannin is nonspecific, causing overt toxicity, which limits its use to research studies. Dalton et al. optimized reversible interactions to design compounds that covalently interacted with the analogous conserved lysine (K779) near the active site of PI3K $\delta$ isoform [104]. PX-866 is a wortmannin analog that also forms a covalent bond with K802 that entered clinical trials but did not show promising efficacy [105]. It remains to be determined whether other type VI PI3K inhibitors will provide an advantage over the current reversible PI3K inhibitors in clinical trials [16].

The success of type VI protein kinase inhibitors has been realized with the development of EGFR- and Bruton's tyrosine kinase (BTK)-targeted compounds. Afatinib, osimertinib, dacomitinib, and neratinib are FDA-approved type VI inhibitors that target the EGFR family and are used to treat a variety of cancers [106] (Fig. 12). All these drugs form a covalent adduct with a key cysteine (C797 for EGFR) in the active site and are expected to improve treatment options especially in patients who develop drug resistance [107, 108]. While the irreversible nature of these compounds provides a more durable inhibitory response, not all type VI inhibitors may be able to overcome the development of acquired drug resistance observed with first generation type I/II reversible inhibitors [109]. Afatinib, which was designed based on the reversible inhibitor gefitinib, is not effective against the common EGFR T790M mutation that is often responsible for acquired drug resistance. 


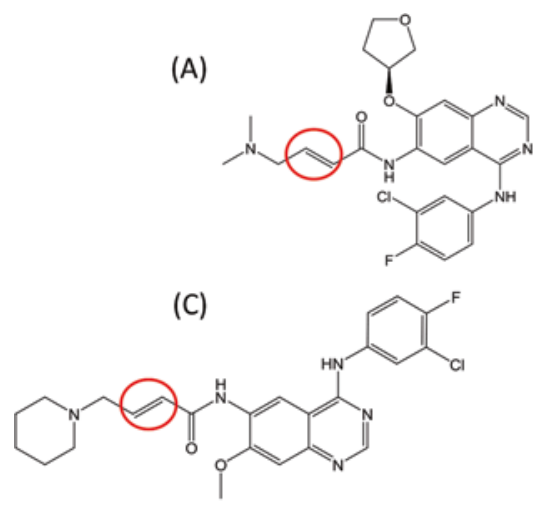

(B)

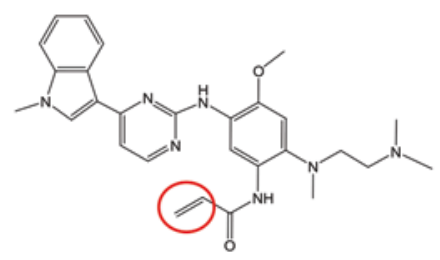

(D)

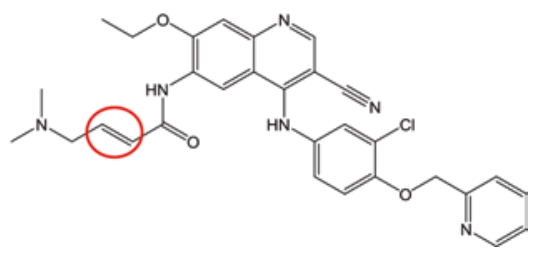

Fig. 12 The chemical structures of (a) afatinib, (b) osimertinib, (c) dacomitinib, and (d) neratinib are shown. The reactive site of the acrylamide moieties is circled in red

In addition to causing the T790M mutation, afatinib resistance mechanisms include increased expression of the c-Met receptor tyrosine kinase and V843I mutation on EGFR [110]. New structures, such as osimertinib, are less restricted by the T790M mutation and may have better treatment outcomes for patients resistant to first-line EGFR inhibitors [109].

Ibrutinib is a type VI inhibitor that forms a covalent bond on cysteine 481 (C481) in the active site of BTK and is used to treat B-cell cancers such as chronic lymphocytic leukemia (CLL) [111]. Several months after treatment, nearly $80 \%$ of relapsing patients contained a cysteine to serine $(\mathrm{C} 481 \mathrm{~S})$ mutation that limited the efficacy of ibrutinib [112]. Alternative reversible BTK targeted compounds that tolerate the C481S mutations are showing promise in treating CLL relapses [113]. Ibrutinib has also been associated with several adverse drug events, which likely occurs due to the covalent interactions with other targets and presents a barrier for its use in some patients. Acalabrutinib is a second-generation type VI BTK inhibitor that targets C481 that reportedly causes fewer adverse events and is showing more sustained patient responses in clinical trials evaluating relapsed or refractory chronic lymphocytic leukemia [114].

The MAP kinases have been the target of several type VI inhibitors. Zhang et al. described the use of the type II kinase inhibitor imatinib to design covalent inhibitors against JNK1/2/3 isoforms [115]. The authors noted that several kinases targeted by imatinib have a potentially reactive cysteine that precedes the DFG motif of the activation loop. By attaching an electrophilic acrylamide, a compound was identified that targeted not only expected tyrosine kinases but also JNK isoforms. Further modifications identified compounds with improved JNK selectivity and potency to allow their use as reagents to examine cellular functions for the JNK pathway [115]. In a study by Ward et al., new reversible ERK1/2 inhibitors, with a pyrimidine scaffold, were identified and modified with an acrylamide functional group to make irreversible covalent inhibitors that targeted C166, which is directly 
adjacent to the DFG motif at the beginning of the active loop [116]. This cysteine is conserved in ERK1/2 but not in p38 or JNK MAP kinases, which is expected to provide some degree of selectivity. More recent studies have identified ERK1/2targeted compounds that form covalent bonds with a cysteine (C159) located in the D-recruitment site (DRS) outside the ATP-binding site [39]. The lead compound, BI-78D3, appears to block interactions between ERK2 and its activator MEK1. Despite C159 being conserved in other MAP kinases, such as p38 and JNK, BI-78D3 modifications were only observed on ERK1/2 suggesting other DRS structural features facilitated selectivity [39].

New approaches for cancer therapy through targeted inhibition of transcriptional regulation by cyclin-dependent kinases (CDKs) have utilized covalent-binding compounds [117]. These studies identified a compound THZ1 that covalently binds to a cysteine (C312) that resides outside of the ATP-binding site and inhibits CDK7, and to a lesser extent CDK12 and 13, phosphorylation of RNA polymerase II. Modifications to THZ1 that improved potency and drug-like properties led to the generation of the covalent CDK7 inhibitor SY-1365, which is currently in cancer clinical trials [118]. A common problem that reduces the efficacy of THZ1 and other drugs is their efflux by the $\mathrm{ABC}$ transporters. Gao et al. provided evidence that upregulation of $\mathrm{ABC}$ transporters by THZ1 can be overcome by compounds that covalently target CDK12 and are not $\mathrm{ABC}$ transporter substrates [119].

Downstream of PI3K, Akt protein kinases have been targeted by covalent inhibitors [120]. Weisner et al. posited that allosteric inhibitors, such as the previously mentioned MK-2206, that targeted the PH-domain were proximal to cysteines that could be targeted to generate selective and irreversible Akt inhibitors [120]. The result of these studies is the compound borussertib, which forms a novel covalent interaction on C296 and has been shown in preclinical studies to be effective in combination with the type III MEK1/2 inhibitor trametinib for inhibiting pancreatic and colorectal cancers expressing KRas mutations [121]. The structure of borussertib in complex with Akt1 is shown in Fig. 13. Borussertib covalently binds C296 and forms hydrophobic interactions between the PH domain and the ATPbinding site.

Covalent type VI protein kinase inhibitors have provided new options for more durable responses and target selectivity. Significant benefits have been observed with type VI inhibitors, such as afatinib and ibrutinib, versus reversible type I/II inhibitors for the treatment of lung cancers [122] and lymphocytic leukemias [123]. Nonetheless, acquired drug resistance through mutations in the targeted cysteine and off-target interactions remain barriers to durable patient outcomes. Expanding the repertoire of amino acids targeted by type VI inhibitors beyond the common cysteine targets may provide advantages. For example, targeting lysine residues in the active site of protein kinases with type VI compounds may be effective at disabling enzyme activity. However, surface-exposed lysines are generally thought to be poor nucleophiles because they are protonated $\left(\mathrm{p} K_{\mathrm{a}} \sim 10.5\right)$ at physiological $\mathrm{pH}$ [100]. Recent studies using computational predictions suggest that localized $\mathrm{p} K_{\mathrm{a}}$ values may shift several units, allowing lysines to be amenable to reacting with 
Fig. 13 Structure of borussertib in complex with Akt1 (PDB: 6HHF). Borussertib (magenta lines) interacts with $\mathrm{C} 296$ (green) and makes hydrophobic interactions with L210, L264, and I290 (cyan). PH domain residues 5-108 (orange), and ATP site residues 156-164 (yellow) are shown

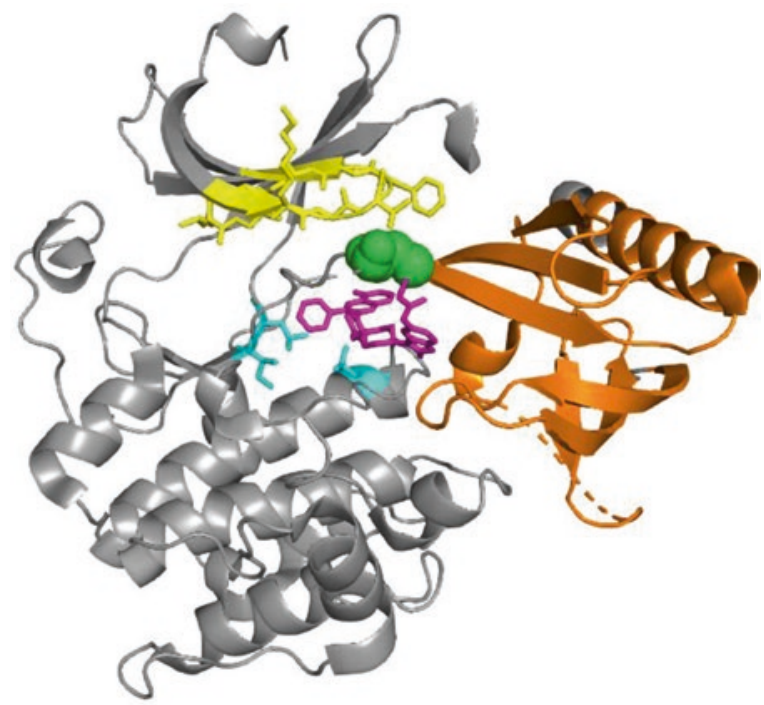

electrophilic warheads [124]. Given the success of current covalent inhibitors targeting EGFR and BTK protein kinases, the future will likely see the development of new type VI inhibitors for treating disease.

\section{References}

1. Mancini, M., \& Yarden, Y. (2016). Mutational and network level mechanisms underlying resistance to anti-cancer kinase inhibitors. Seminars in Cell \& Developmental Biology, 50, 164-176.

2. Dudley, D. T., Pang, L., Decker, S. J., Bridges, A. J., \& Saltiel, A. R. (1995). A synthetic inhibitor of the mitogen-activated protein kinase cascade. Proceedings of the National Academy of Sciences of the United States of America, 92, 7686-7689.

3. Sebolt-Leopold, J. S., Dudley, D. T., Herrera, R., Van Becelaere, K., Wiland, A., Gowan, R. C., Tecle, H., Barrett, S. D., Bridges, A., Przybranowski, S., Leopold, W. R., \& Saltiel, A. R. (1999). Blockade of the MAP kinase pathway suppresses growth of colon tumors in vivo. Nature Medicine, 5, 810-816.

4. Ohren, J. F., Chen, H., Pavlovsky, A., Whitehead, C., Zhang, E., Kuffa, P., Yan, C., McConnell, P., Spessard, C., Banotai, C., Mueller, W. T., Delaney, A., Omer, C., Sebolt-Leopold, J., Dudley, D. T., Leung, I. K., Flamme, C., Warmus, J., Kaufman, M., Barrett, S., Tecle, H., \& Hasemann, C. A. (2004). Structures of human MAP kinase kinase 1 (MEK1) and MEK2 describe novel noncompetitive kinase inhibition. Nature Structural \& Molecular Biology, 11, 1192-1197.

5. Zhao, Y., \& Adjei, A. A. (2014). The clinical development of MEK inhibitors. Nature Reviews Clinical Oncology, 11, 385-400.

6. Davies, H., Bignell, G. R., Cox, C., Stephens, P., Edkins, S., Clegg, S., Teague, J., Woffendin, H., Garnett, M. J., Bottomley, W., Davis, N., Dicks, E., Ewing, R., Floyd, Y., Gray, K., Hall, 
S., Hawes, R., Hughes, J., Kosmidou, V., Menzies, A., Mould, C., Parker, A., Stevens, C., Watt, S., Hooper, S., Wilson, R., Jayatilake, H., Gusterson, B. A., Cooper, C., Shipley, J., Hargrave, D., Pritchard-Jones, K., Maitland, N., Chenevix-Trench, G., Riggins, G. J., Bigner, D. D., Palmieri, G., Cossu, A., Flanagan, A., Nicholson, A., Ho, J. W., Leung, S. Y., Yuen, S. T., Weber, B. L., Seigler, H. F., Darrow, T. L., Paterson, H., Marais, R., Marshall, C. J., Wooster, R., Stratton, M. R., \& Futreal, P. A. (2002). Mutations of the BRAF gene in human cancer. Nature, 417, 949-954.

7. Larkin, J., Ascierto, P. A., Dreno, B., Atkinson, V., Liszkay, G., Maio, M., Mandala, M., Demidov, L., Stroyakovskiy, D., Thomas, L., de la Cruz-Merino, L., Dutriaux, C., Garbe, C., Sovak, M. A., Chang, I., Choong, N., Hack, S. P., McArthur, G. A., \& Ribas, A. (2014). Combined vemurafenib and cobimetinib in BRAF-mutated melanoma. The New England Journal of Medicine, 371, 1867-1876.

8. Khunger, A., Khunger, M., \& Velcheti, V. (2018). Dabrafenib in combination with trametinib in the treatment of patients with BRAF V600-positive advanced or metastatic non-small cell lung cancer: Clinical evidence and experience. Therapeutic Advances in Respiratory Disease, 12, 1753466618767611.

9. Ljubas, J., Ovesen, T., \& Rusan, M. (2019). A systematic review of phase II targeted therapy clinical trials in anaplastic thyroid cancer. Cancers (Basel), 11(7), 943.

10. Long, G. V., Stroyakovskiy, D., Gogas, H., Levchenko, E., de Braud, F., Larkin, J., Garbe, C., Jouary, T., Hauschild, A., Grob, J. J., Chiarion-Sileni, V., Lebbe, C., Mandala, M., Millward, M., Arance, A., Bondarenko, I., Haanen, J. B., Hansson, J., Utikal, J., Ferraresi, V., Kovalenko, N., Mohr, P., Probachai, V., Schadendorf, D., Nathan, P., Robert, C., Ribas, A., DeMarini, D. J., Irani, J. G., Swann, S., Legos, J. J., Jin, F., Mookerjee, B., \& Flaherty, K. (2015). Dabrafenib and trametinib versus dabrafenib and placebo for Val600 BRAF-mutant melanoma: A multicentre, double-blind, phase 3 randomised controlled trial. Lancet, 386, $444-451$.

11. Zhao, Z., Xie, L., \& Bourne, P. E. (2017). Insights into the binding mode of MEK type-III inhibitors. A step towards discovering and designing allosteric kinase inhibitors across the human kinome. PLoS One, 12, e0179936.

12. Garnett, M. J., Rana, S., Paterson, H., Barford, D., \& Marais, R. (2005). Wild-type and mutant B-RAF activate C-RAF through distinct mechanisms involving heterodimerization. Molecular Cell, 20, 963-969.

13. Hatzivassiliou, G., Haling, J. R., Chen, H., Song, K., Price, S., Heald, R., Hewitt, J. F., Zak, M., Peck, A., Orr, C., Merchant, M., Hoeflich, K. P., Chan, J., Luoh, S. M., Anderson, D. J., Ludlam, M. J., Wiesmann, C., Ultsch, M., Friedman, L. S., Malek, S., \& Belvin, M. (2013). Mechanism of MEK inhibition determines efficacy in mutant KRAS- versus BRAF-driven cancers. Nature, 501, 232-236.

14. Janku, F., Yap, T. A., \& Meric-Bernstam, F. (2018). Targeting the PI3K pathway in cancer: Are we making headway? Nature Reviews Clinical Oncology, 15, 273-291.

15. Downward, J. (1998). Mechanisms and consequences of activation of protein kinase B/Akt. Current Opinion in Cell Biology, 10, 262-267.

16. Yang, J., Nie, J., Ma, X., Wei, Y., Peng, Y., \& Wei, X. (2019). Targeting PI3K in cancer: Mechanisms and advances in clinical trials. Molecular Cancer, 18, 26.

17. Wu, W. I., Voegtli, W. C., Sturgis, H. L., Dizon, F. P., Vigers, G. P., \& Brandhuber, B. J. (2010). Crystal structure of human AKT1 with an allosteric inhibitor reveals a new mode of kinase inhibition. PLoS One, 5, e12913.

18. Barnett, S. F., Defeo-Jones, D., Fu, S., Hancock, P. J., Haskell, K. M., Jones, R. E., Kahana, J. A., Kral, A. M., Leander, K., Lee, L. L., Malinowski, J., McAvoy, E. M., Nahas, D. D., Robinson, R. G., \& Huber, H. E. (2005). Identification and characterization of pleckstrinhomology-domain-dependent and isoenzyme-specific Akt inhibitors. The Biochemical Journal, 385, 399-408.

19. Hirai, H., Sootome, H., Nakatsuru, Y., Miyama, K., Taguchi, S., Tsujioka, K., Ueno, Y., Hatch, H., Majumder, P. K., Pan, B. S., \& Kotani, H. (2010). MK-2206, an allosteric Akt 
inhibitor, enhances antitumor efficacy by standard chemotherapeutic agents or molecular targeted drugs in vitro and in vivo. Molecular Cancer Therapeutics, 9, 1956-1967.

20. Politz, O., Siegel, F., Barfacker, L., Bomer, U., Hagebarth, A., Scott, W. J., Michels, M., Ince, S., Neuhaus, R., Meyer, K., Fernandez-Montalvan, A. E., Liu, N., von Nussbaum, F., Mumberg, D., \& Ziegelbauer, K. (2017). BAY 1125976, a selective allosteric AKT1/2 inhibitor, exhibits high efficacy on AKT signaling-dependent tumor growth in mouse models. International Journal of Cancer, 140, 449-459.

21. Lapierre, J. M., Eathiraj, S., Vensel, D., Liu, Y., Bull, C. O., Cornell-Kennon, S., Iimura, S., Kelleher, E. W., Kizer, D. E., Koerner, S., Makhija, S., Matsuda, A., Moussa, M., Namdev, N., Savage, R. E., Szwaya, J., Volckova, E., Westlund, N., Wu, H., \& Schwartz, B. (2016). Discovery of 3-(3-(4-(1-Aminocyclobutyl)phenyl)-5-phenyl-3H-imidazo[4,5-b]pyridin-2-yl) pyridin-2-amine (ARQ 092): An orally bioavailable, selective, and potent allosteric AKT inhibitor. Journal of Medicinal Chemistry, 59, 6455-6469.

22. Leoni, C., Gullo, G., Resta, N., Fagotti, A., Onesimo, R., Schwartz, B., Kazakin, J., Abbadessa, G., Crown, J., Collins, C. D., Ranieri, C., Scambia, G., \& Zampino, G. (2019). First evidence of a therapeutic effect of miransertib in a teenager with Proteus syndrome and ovarian carcinoma. American Journal of Medical Genetics Part A, 179, 1319-1324.

23. Keppler-Noreuil, K. M., Sapp, J. C., Lindhurst, M. J., Darling, T. N., Burton-Akright, J., Bagheri, M., Dombi, E., Gruber, A., Jarosinski, P. F., Martin, S., Nathan, N., Paul, S. M., Savage, R. E., Wolters, P. L., Schwartz, B., Widemann, B. C., \& Biesecker, L. G. (2019). Pharmacodynamic study of miransertib in individuals with proteus syndrome. American Journal of Human Genetics, 104, 484-491.

24. Reichardt, L. F. (2006). Neurotrophin-regulated signalling pathways. Philosophical Transactions of the Royal Society of London. Series B, Biological Sciences, 361, 1545-1564.

25. Demir, I. E., Tieftrunk, E., Schorn, S., Friess, H., \& Ceyhan, G. O. (2016). Nerve growth factor \& TrkA as novel therapeutic targets in cancer. Biochimica et Biophysica Acta, 1866, $37-50$.

26. Lange, A. M., \& Lo, H. W. (2018). Inhibiting TRK proteins in clinical cancer therapy. Cancers (Basel), 10(4), 105.

27. Bhangoo, M. S., \& Sigal, D. (2019). TRK inhibitors: Clinical development of larotrectinib. Current Oncology Reports, 21, 14.

28. Hirose, M., Kuroda, Y., \& Murata, E. (2016). NGF/TrkA signaling as a therapeutic target for pain. Pain Practice, 16, 175-182.

29. Bagal, S. K., Omoto, K., Blakemore, D. C., Bungay, P. J., Bilsland, J. G., Clarke, P. J., Corbett, M. S., Cronin, C. N., Cui, J. J., Dias, R., Flanagan, N. J., Greasley, S. E., Grimley, R., Johnson, E., Fengas, D., Kitching, L., Kraus, M. L., McAlpine, I., Nagata, A., Waldron, G. J., \& Warmus, J. S. (2019). Discovery of allosteric, potent, subtype selective, and peripherally restricted TrkA kinase inhibitors. Journal of Medicinal Chemistry, 62, 247-265.

30. Fasano, M., Della Corte, C. M., Califano, R., Capuano, A., Troiani, T., Martinelli, E., Ciardiello, F., \& Morgillo, F. (2014). Type III or allosteric kinase inhibitors for the treatment of non-small cell lung cancer. Expert Opinion on Investigational Drugs, 23, 809-821.

31. Rastelli, G., Anighoro, A., Chripkova, M., Carrassa, L., \& Broggini, M. (2014). Structurebased discovery of the first allosteric inhibitors of cyclin-dependent kinase 2. Cell Cycle, 13, 2296-2305.

32. Gao, Y., Zhang, P., Cui, A., Ye, D. Y., Xiang, M., \& Chu, Y. (2018). Discovery and antiinflammatory evaluation of benzothiazepinones (BTZs) as novel non-ATP competitive inhibitors of glycogen synthase kinase-3beta (GSK-3beta). Bioorganic \& Medicinal Chemistry, 26, 5479-5493.

33. Yueh, C., Rettenmaier, J., Xia, B., Hall, D. R., Alekseenko, A., Porter, K. A., Barkovich, K., Keseru, G., Whitty, A., Wells, J. A., Vajda, S., \& Kozakov, D. (2019). Kinase atlas: Druggability analysis of potential allosteric sites in kinases. Journal of Medicinal Chemistry, $62,6512-6524$. 
34. Kozakov, D., Grove, L. E., Hall, D. R., Bohnuud, T., Mottarella, S. E., Luo, L., Xia, B., Beglov, D., \& Vajda, S. (2015). The FTMap family of web servers for determining and characterizing ligand-binding hot spots of proteins. Nature Protocols, 10, 733-755.

35. Wu, P., Clausen, M. H., \& Nielsen, T. E. (2015). Allosteric small-molecule kinase inhibitors. Pharmacology \& Therapeutics, 156, 59-68.

36. Hancock, C. N., Macias, A., Lee, E. K., Yu, S. Y., Mackerell, A. D., Jr., \& Shapiro, P. (2005). Identification of novel extracellular signal-regulated kinase docking domain inhibitors. Journal of Medicinal Chemistry, 48, 4586-4595.

37. Chen, F., Hancock, C. N., Macias, A. T., Joh, J., Still, K., Zhong, S., MacKerell, A. D., Jr., \& Shapiro, P. (2006). Characterization of ATP-independent ERK inhibitors identified through in silico analysis of the active ERK2 structure. Bioorganic \& Medicinal Chemistry Letters, 16, 6281-6287.

38. Sammons, R. M., Perry, N. A., Li, Y., Cho, E. J., Piserchio, A., Zamora-Olivares, D. P., Ghose, R., Kaoud, T. S., Debevec, G., Bartholomeusz, C., Gurevich, V. V., Iverson, T. M., Giulianotti, M., Houghten, R. A., \& Dalby, K. N. (2019). A novel class of common docking domain inhibitors that prevent ERK2 activation and substrate phosphorylation. ACS Chemical Biology, 14, 1183-1194.

39. Kaoud, T. S., Johnson, W. H., Ebelt, N. D., Piserchio, A., Zamora-Olivares, D., Van Ravenstein, S. X., Pridgen, J. R., Edupuganti, R., Sammons, R., Cano, M., Warthaka, M., Harger, M., Tavares, C. D. J., Park, J., Radwan, M. F., Ren, P., Anslyn, E. V., Tsai, K. Y., Ghose, R., \& Dalby, K. N. (2019). Modulating multi-functional ERK complexes by covalent targeting of a recruitment site in vivo. Nature Communications, 10, 5232.

40. Samadani, R., Zhang, J., Brophy, A., Oashi, T., Priyakumar, U. D., Raman, E. P., St John, F. J., Jung, K. Y., Fletcher, S., Pozharski, E., MacKerell, A. D., Jr., \& Shapiro, P. (2015). Small-molecule inhibitors of ERK-mediated immediate early gene expression and proliferation of melanoma cells expressing mutated BRaf. The Biochemical Journal, 467, 425-438.

41. Nitta, R. T., Chu, A. H., \& Wong, A. J. (2008). Constitutive activity of JNK2 alpha2 is dependent on a unique mechanism of MAPK activation. The Journal of Biological Chemistry, 283, 34935-34945.

42. Khokhlatchev, A. V., Canagarajah, B., Wilsbacher, J., Robinson, M., Atkinson, M., Goldsmith, E., \& Cobb, M. H. (1998). Phosphorylation of the MAP kinase ERK2 promotes its homodimerization and nuclear translocation. Cell, 93, 605-615.

43. Kaoud, T. S., Devkota, A. K., Harris, R., Rana, M. S., Abramczyk, O., Warthaka, M., Lee, S., Girvin, M. E., Riggs, A. F., \& Dalby, K. N. (2011). Activated ERK2 is a monomer in vitro with or without divalent cations and when complexed to the cytoplasmic scaffold PEA-15. Biochemistry, 50, 4568-4578.

44. Lidke, D. S., Huang, F., Post, J. N., Rieger, B., Wilsbacher, J., Thomas, J. L., Pouyssegur, J., Jovin, T. M., \& Lenormand, P. (2010). ERK nuclear translocation is dimerization-independent but controlled by the rate of phosphorylation. The Journal of Biological Chemistry, 285, 3092-3102.

45. Casar, B., Pinto, A., \& Crespo, P. (2008). Essential role of ERK dimers in the activation of cytoplasmic but not nuclear substrates by ERK-scaffold complexes. Molecular Cell, 31, 708-721.

46. Herrero, A., Pinto, A., Colon-Bolea, P., Casar, B., Jones, M., Agudo-Ibanez, L., Vidal, R., Tenbaum, S. P., Nuciforo, P., Valdizan, E. M., Horvath, Z., Orfi, L., Pineda-Lucena, A., Bony, E., Keri, G., Rivas, G., Pazos, A., Gozalbes, R., Palmer, H. G., Hurlstone, A., \& Crespo, P. (2015). Small molecule inhibition of ERK dimerization prevents tumorigenesis by RASERK pathway oncogenes. Cancer Cell, 28, 170-182.

47. Wilsbacher, J. L., Juang, Y. C., Khokhlatchev, A. V., Gallagher, E., Binns, D., Goldsmith, E. J., \& Cobb, M. H. (2006). Characterization of mitogen-activated protein kinase (MAPK) dimers. Biochemistry, 45, 13175-13182.

48. Beneker, C. M., Rovoli, M., Kontopidis, G., Roring, M., Galda, S., Braun, S., Brummer, T., \& McInnes, C. (2019). Design and synthesis of type-IV inhibitors of BRAF kinase that 
block dimerization and overcome paradoxical MEK/ERK activation. Journal of Medicinal Chemistry, 62, 3886-3897.

49. Poulikakos, P. I., Zhang, C., Bollag, G., Shokat, K. M., \& Rosen, N. (2010). RAF inhibitors transactivate RAF dimers and ERK signalling in cells with wild-type BRAF. Nature, 464, $427-430$.

50. Kaneto, H. (2005). The JNK pathway as a therapeutic target for diabetes. Expert Opinion on Therapeutic Targets, 9, 581-592.

51. Stebbins, J. L., De, S. K., Machleidt, T., Becattini, B., Vazquez, J., Kuntzen, C., Chen, L. H., Cellitti, J. F., Riel-Mehan, M., Emdadi, A., Solinas, G., Karin, M., \& Pellecchia, M. (2008). Identification of a new JNK inhibitor targeting the JNK-JIP interaction site. Proceedings of the National Academy of Sciences of the United States of America, 105, 16809-16813.

52. Comess, K. M., Sun, C., Abad-Zapatero, C., Goedken, E. R., Gum, R. J., Borhani, D. W., Argiriadi, M., Groebe, D. R., Jia, Y., Clampit, J. E., Haasch, D. L., Smith, H. T., Wang, S., Song, D., Coen, M. L., Cloutier, T. E., Tang, H., Cheng, X., Quinn, C., Liu, B., Xin, Z., Liu, G., Fry, E. H., Stoll, V., Ng, T. I., Banach, D., Marcotte, D., Burns, D. J., Calderwood, D. J., \& Hajduk, P. J. (2011). Discovery and characterization of non-ATP site inhibitors of the mitogen activated protein (MAP) kinases. ACS Chemical Biology, 6, 234-244.

53. Liu, X., Zhang, C. S., Lu, C., Lin, S. C., Wu, J. W., \& Wang, Z. X. (2016). A conserved motif in JNK/p38-specific MAPK phosphatases as a determinant for JNK1 recognition and inactivation. Nature Communications, 7, 10879.

54. Chiquet, C., Aptel, F., Creuzot-Garcher, C., Berrod, J. P., Kodjikian, L., Massin, P., Deloche, C., Perino, J., Kirwan, B. A., de Brouwer, S., Combette, J. M., \& Behar-Cohen, F. (2017). Postoperative ocular inflammation: A single subconjunctival injection of XG-102 compared to dexamethasone drops in a randomized trial. American Journal of Ophthalmology, 174, $76-84$.

55. Gourmaud, S., Thomas, P., Thomasseau, S., Tible, M., Abadie, C., Paquet, C., \& Hugon, J. (2018). Brimapitide reduced neuronal stress markers and cognitive deficits in 5XFAD transgenic mice. Journal of Alzheimer's disease, 63, 665-674.

56. Eshraghi, A. A., Aranke, M., Salvi, R., Ding, D., Coleman, J. K. M., Jr., Ocak, E., Mittal, R., \& Meyer, T. (2018). Preclinical and clinical otoprotective applications of cell-penetrating peptide D-JNKI-1 (AM-111). Hearing Research, 368, 86-91.

57. Staecker, H., Jokovic, G., Karpishchenko, S., Kienle-Gogolok, A., Krzyzaniak, A., Lin, C. D., Navratil, P., Tzvetkov, V., Wright, N., \& Meyer, T. (2019). Efficacy and safety of AM-111 in the treatment of acute unilateral sudden deafness-a double-blind, randomized, placebo-controlled phase 3 study. Otology \& Neurotology, 40, 584-594.

58. Xing, L. (2015). Clinical candidates of small molecule p38 MAPK inhibitors for inflammatory disease. MAP Kinase, 4, 24-30.

59. Shah, N. G., Tulapurkar, M. E., Ramarathnam, A., Brophy, A., Martinez, R., 3rd, Hom, K., Hodges, T., Samadani, R., Singh, I. S., MacKerell, A. D., Jr., Shapiro, P., \& Hasday, J. D. (2017). Novel noncatalytic substrate-selective p38alpha-specific MAPK inhibitors with endothelial-stabilizing and anti-inflammatory activity. Journal of Immunology, 198, 3296-3306.

60. O’Keefe, S. J., Mudgett, J. S., Cupo, S., Parsons, J. N., Chartrain, N. A., Fitzgerald, C., Chen, S. L., Lowitz, K., Rasa, C., Visco, D., Luell, S., Carballo-Jane, E., Owens, K., \& Zaller, D. M. (2007). Chemical genetics define the roles of p38alpha and p38beta in acute and chronic inflammation. The Journal of Biological Chemistry, 282, 34663-34671.

61. Ferrari, G., Terushkin, V., Wolff, M. J., Zhang, X., Valacca, C., Poggio, P., Pintucci, G., \& Mignatti, P. (2012). TGF-beta1 induces endothelial cell apoptosis by shifting VEGF activation of p38(MAPK) from the prosurvival p38beta to proapoptotic p38alpha. Molecular Cancer Research, 10, 605-614.

62. Kim, C., Sano, Y., Todorova, K., Carlson, B. A., Arpa, L., Celada, A., Lawrence, T., Otsu, K., Brissette, J. L., Arthur, J. S., \& Park, J. M. (2008). The kinase p38 alpha serves cell 
type-specific inflammatory functions in skin injury and coordinates pro- and anti-inflammatory gene expression. Nature Immunology, 9, 1019-1027.

63. Zhang, J., Adrian, F. J., Jahnke, W., Cowan-Jacob, S. W., Li, A. G., Iacob, R. E., Sim, T., Powers, J., Dierks, C., Sun, F., Guo, G. R., Ding, Q., Okram, B., Choi, Y., Wojciechowski, A., Deng, X., Liu, G., Fendrich, G., Strauss, A., Vajpai, N., Grzesiek, S., Tuntland, T., Liu, Y., Bursulaya, B., Azam, M., Manley, P. W., Engen, J. R., Daley, G. Q., Warmuth, M., \& Gray, N. S. (2010). Targeting Bcr-Abl by combining allosteric with ATP-binding-site inhibitors. Nature, 463, 501-506.

64. Adrian, F. J., Ding, Q., Sim, T., Velentza, A., Sloan, C., Liu, Y., Zhang, G., Hur, W., Ding, S., Manley, P., Mestan, J., Fabbro, D., \& Gray, N. S. (2006). Allosteric inhibitors of Bcr-abldependent cell proliferation. Nature Chemical Biology, 2, 95-102.

65. Rossari, F., Minutolo, F., \& Orciuolo, E. (2018). Past, present, and future of Bcr-Abl inhibitors: From chemical development to clinical efficacy. Journal of Hematology \& Oncology, $11,84$.

66. Maurer-Stroh, S., Gouda, M., Novatchkova, M., Schleiffer, A., Schneider, G., Sirota, F. L., Wildpaner, M., Hayashi, N., \& Eisenhaber, F. (2004). MYRbase: Analysis of genome-wide glycine myristoylation enlarges the functional spectrum of eukaryotic myristoylated proteins. Genome Biology, 5, R21.

67. Yang, J., Campobasso, N., Biju, M. P., Fisher, K., Pan, X. Q., Cottom, J., Galbraith, S., Ho, T., Zhang, H., Hong, X., Ward, P., Hofmann, G., Siegfried, B., Zappacosta, F., Washio, Y., Cao, P., Qu, J., Bertrand, S., Wang, D. Y., Head, M. S., Li, H., Moores, S., Lai, Z., Johanson, K., Burton, G., Erickson-Miller, C., Simpson, G., Tummino, P., Copeland, R. A., \& Oliff, A. (2011). Discovery and characterization of a cell-permeable, small-molecule c-Abl kinase activator that binds to the myristoyl binding site. Chemistry \& Biology, 18, 177-186.

68. Noren, N. K., Foos, G., Hauser, C. A., \& Pasquale, E. B. (2006). The EphB4 receptor suppresses breast cancer cell tumorigenicity through an Abl-Crk pathway. Nature Cell Biology, $8,815-825$.

69. Mora, A., Komander, D., van Aalten, D. M., \& Alessi, D. R. (2004). PDK1, the master regulator of AGC kinase signal transduction. Seminars in Cell \& Developmental Biology, 15, $161-170$.

70. Biondi, R. M., Kieloch, A., Currie, R. A., Deak, M., \& Alessi, D. R. (2001). The PIF-binding pocket in PDK1 is essential for activation of S6K and SGK, but not PKB. The EMBO Journal, 20, 4380-4390.

71. Rettenmaier, T. J., Sadowsky, J. D., Thomsen, N. D., Chen, S. C., Doak, A. K., Arkin, M. R., \& Wells, J. A. (2014). A small-molecule mimic of a peptide docking motif inhibits the protein kinase PDK1. Proceedings of the National Academy of Sciences of the United States of America, 111, 18590-18595.

72. Medina, J. R., Becker, C. J., Blackledge, C. W., Duquenne, C., Feng, Y., Grant, S. W., Heerding, D., Li, W. H., Miller, W. H., Romeril, S. P., Scherzer, D., Shu, A., Bobko, M. A., Chadderton, A. R., Dumble, M., Gardiner, C. M., Gilbert, S., Liu, Q., Rabindran, S. K., Sudakin, V., Xiang, H., Brady, P. G., Campobasso, N., Ward, P., \& Axten, J. M. (2011). Structure-based design of potent and selective 3-phosphoinositide-dependent kinase-1 (PDK1) inhibitors. Journal of Medicinal Chemistry, 54, 1871-1895.

73. Betzi, S., Alam, R., Martin, M., Lubbers, D. J., Han, H., Jakkaraj, S. R., Georg, G. I., \& Schonbrunn, E. (2011). Discovery of a potential allosteric ligand binding site in CDK2. ACS Chemical Biology, 6, 492-501.

74. Powell, J. D., Pollizzi, K. N., Heikamp, E. B., \& Horton, M. R. (2012). Regulation of immune responses by mTOR. Annual Review of Immunology, 30, 39-68.

75. Li, J., Kim, S. G., \& Blenis, J. (2014). Rapamycin: One drug, many effects. Cell Metabolism, 19, 373-379.

76. Hausch, F., Kozany, C., Theodoropoulou, M., \& Fabian, A. K. (2013). FKBPs and the Akt/ mTOR pathway. Cell Cycle, 12, 2366-2370. 
77. Tak, P. P., \& Firestein, G. S. (2001). NF-kappaB: A key role in inflammatory diseases. The Journal of Clinical Investigation, 107, 7-11.

78. Gupta, S. C., Sundaram, C., Reuter, S., \& Aggarwal, B. B. (2010). Inhibiting NF-kappaB activation by small molecules as a therapeutic strategy. Biochimica et Biophysica Acta, 1799, 775-787.

79. Burke, J. R., Pattoli, M. A., Gregor, K. R., Brassil, P. J., MacMaster, J. F., McIntyre, K. W., Yang, X., Iotzova, V. S., Clarke, W., Strnad, J., Qiu, Y., \& Zusi, F. C. (2003). BMS-345541 is a highly selective inhibitor of I kappa B kinase that binds at an allosteric site of the enzyme and blocks NF-kappa B-dependent transcription in mice. The Journal of Biological Chemistry, $278,1450-1456$.

80. Gower, C. M., Chang, M. E., \& Maly, D. J. (2014). Bivalent inhibitors of protein kinases. Critical Reviews in Biochemistry and Molecular Biology, 49, 102-115.

81. Profit, A. A., Lee, T. R., \& Lawrence, D. S. (1999). Bivalent inhibitors of protein tyrosine kinases. Journal of the American Chemical Society, 121, 280-283.

82. Xu, W., Doshi, A., Lei, M., Eck, M. J., \& Harrison, S. C. (1999). Crystal structures of c-Src reveal features of its autoinhibitory mechanism. Molecular Cell, 3, 629-638.

83. Brandvold, K. R., Santos, S. M., Breen, M. E., Lachacz, E. J., Steffey, M. E., \& Soellner, M. B. (2015). Exquisitely specific bisubstrate inhibitors of c-Src kinase. ACS Chemical Biology, 10, 1387-1391.

84. Johnson, T. K., \& Soellner, M. B. (2016). Bivalent inhibitors of c-Src tyrosine kinase that bind a regulatory domain. Bioconjugate Chemistry, 27, 1745-1749.

85. Hill, Z. B., Perera, B. G., \& Maly, D. J. (2009). A chemical genetic method for generating bivalent inhibitors of protein kinases. Journal of the American Chemical Society, 131, 6686-6688.

86. Hill, Z. B., Perera, B. G., Andrews, S. S., \& Maly, D. J. (2012). Targeting diverse signaling interaction sites allows the rapid generation of bivalent kinase inhibitors. ACS Chemical Biology, 7, 487-495.

87. Hill, Z. B., Perera, B. G., \& Maly, D. J. (2011). Bivalent inhibitors of the tyrosine kinases ABL and SRC: Determinants of potency and selectivity. Molecular BioSystems, 7, 447-456.

88. Tiwari, R., \& Parang, K. (2009). Protein conjugates of SH3-domain ligands and ATPcompetitive inhibitors as bivalent inhibitors of protein kinases. Chembiochem, 10, 2445-2448.

89. Gower, C. M., Thomas, J. R., Harrington, E., Murphy, J., Chang, M. E., Cornella-Taracido, I., Jain, R. K., Schirle, M., \& Maly, D. J. (2016). Conversion of a single polypharmacological agent into selective bivalent inhibitors of intracellular kinase activity. ACS Chemical Biology, $11,121-131$.

90. Wong, M. L., Murphy, J., Harrington, E., Gower, C. M., Jain, R. K., Schirle, M., \& Thomas, J. R. (2016). Examining the influence of specificity ligands and ATP-competitive ligands on the overall effectiveness of bivalent kinase inhibitors. Proteome Science, 15, 17.

91. Stebbins, J. L., De, S. K., Pavlickova, P., Chen, V., Machleidt, T., Chen, L. H., Kuntzen, C., Kitada, S., Karin, M., \& Pellecchia, M. (2011). Design and characterization of a potent and selective dual ATP- and substrate-competitive subnanomolar bidentate c-Jun N-terminal kinase (JNK) inhibitor. Journal of Medicinal Chemistry, 54, 6206-6214.

92. Lechtenberg, B. C., Mace, P. D., Sessions, E. H., Williamson, R., Stalder, R., Wallez, Y., Roth, G. P., Riedl, S. J., \& Pasquale, E. B. (2017). Structure-guided strategy for the development of potent bivalent ERK inhibitors. ACS Medicinal Chemistry Letters, 8, 726-731.

93. Toyama, K., Kobayakawa, T., Nomura, W., \& Tamamura, H. (2018). Inhibition of EGFR activation by bivalent ligands based on a cyclic peptide mimicking the dimerization arm structure of EGFR. Chemical \& Pharmaceutical Bulletin, 66, 1083-1089.

94. Kedika, S. R., \& Udugamasooriya, D. G. (2018). Converting a weaker ATP-binding site inhibitor into a potent hetero-bivalent ligand by tethering to a unique peptide sequence derived from the same kinase. Organic \& Biomolecular Chemistry, 16, 6443-6449.

95. Asati, V., Mahapatra, D. K., \& Bharti, S. K. (2019). PIM kinase inhibitors: Structural and pharmacological perspectives. European Journal of Medicinal Chemistry, 172, 95-108. 
96. Ekambaram, R., Enkvist, E., Vaasa, A., Kasari, M., Raidaru, G., Knapp, S., \& Uri, A. (2013). Selective bisubstrate inhibitors with sub-nanomolar affinity for protein kinase Pim-1. ChemMedChem, 8, 909-913.

97. Lewis, A. L., \& Richard, J. (2015). Challenges in the delivery of peptide drugs: An industry perspective. Therapeutic Delivery, 6, 149-163.

98. Vane, J. R., \& Botting, R. M. (2003). The mechanism of action of aspirin. Thrombosis Research, 110, 255-258.

99. Zhao, Z., \& Bourne, P. E. (2018). Progress with covalent small-molecule kinase inhibitors. Drug Discovery Today, 23, 727-735.

100. Gehringer, M., \& Laufer, S. A. (2019). Emerging and re-emerging warheads for targeted covalent inhibitors: Applications in medicinal chemistry and chemical biology. Journal of Medicinal Chemistry, 62, 5673-5724.

101. Serafimova, I. M., Pufall, M. A., Krishnan, S., Duda, K., Cohen, M. S., Maglathlin, R. L., McFarland, J. M., Miller, R. M., Frodin, M., \& Taunton, J. (2012). Reversible targeting of noncatalytic cysteines with chemically tuned electrophiles. Nature Chemical Biology, 8, 471-476.

102. Krishnan, S., Miller, R. M., Tian, B., Mullins, R. D., Jacobson, M. P., \& Taunton, J. (2014). Design of reversible, cysteine-targeted Michael acceptors guided by kinetic and computational analysis. Journal of the American Chemical Society, 136, 12624-12630.

103. Wymann, M. P., Bulgarelli-Leva, G., Zvelebil, M. J., Pirola, L., Vanhaesebroeck, B., Waterfield, M. D., \& Panayotou, G. (1996). Wortmannin inactivates phosphoinositide 3-kinase by covalent modification of Lys-802, a residue involved in the phosphate transfer reaction. Molecular and Cellular Biology, 16, 1722-1733.

104. Dalton, S. E., Dittus, L., Thomas, D. A., Convery, M. A., Nunes, J., Bush, J. T., Evans, J. P., Werner, T., Bantscheff, M., Murphy, J. A., \& Campos, S. (2018). Selectively targeting the kinome-conserved lysine of PI3Kdelta as a general approach to covalent kinase inhibition. Journal of the American Chemical Society, 140, 932-939.

105. Pitz, M. W., Eisenhauer, E. A., MacNeil, M. V., Thiessen, B., Easaw, J. C., Macdonald, D. R., Eisenstat, D. D., Kakumanu, A. S., Salim, M., Chalchal, H., Squire, J., Tsao, M. S., KamelReid, S., Banerji, S., Tu, D., Powers, J., Hausman, D. F., \& Mason, W. P. (2015). Phase II study of PX-866 in recurrent glioblastoma. Neuro-Oncology, 17, 1270-1274.

106. Roskoski, R., Jr. (2019). Small molecule inhibitors targeting the EGFR/ErbB family of protein-tyrosine kinases in human cancers. Pharmacological Research, 139, 395-411.

107. Tomassi, S., Lategahn, J., Engel, J., Keul, M., Tumbrink, H. L., Ketzer, J., Muhlenberg, T., Baumann, M., Schultz-Fademrecht, C., Bauer, S., \& Rauh, D. (2017). Indazole-based covalent inhibitors to target drug-resistant epidermal growth factor receptor. Journal of Medicinal Chemistry, 60, 2361-2372.

108. Landi, L., \& Cappuzzo, F. (2013). Irreversible EGFR-TKIs: Dreaming perfection. Translational Lung Cancer Research, 2, 40-49.

109. Engel, J., Lategahn, J., \& Rauh, D. (2016). Hope and disappointment: Covalent inhibitors to overcome drug resistance in non-small cell lung cancer. ACS Medicinal Chemistry Letters, 7 , $2-5$.

110. van der Wekken, A. J., Saber, A., Hiltermann, T. J., Kok, K., van den Berg, A., \& Groen, H. J. (2016). Resistance mechanisms after tyrosine kinase inhibitors afatinib and crizotinib in nonsmall cell lung cancer, a review of the literature. Critical Reviews in Oncology/Hematology, 100, 107-116.

111. Roskoski, R., Jr. (2016). Ibrutinib inhibition of bruton protein-tyrosine kinase (BTK) in the treatment of B cell neoplasms. Pharmacological Research, 113, 395-408.

112. Woyach, J. A., Ruppert, A. S., Guinn, D., Lehman, A., Blachly, J. S., Lozanski, A., Heerema, N. A., Zhao, W., Coleman, J., Jones, D., Abruzzo, L., Gordon, A., Mantel, R., Smith, L. L., McWhorter, S., Davis, M., Doong, T. J., Ny, F., Lucas, M., Chase, W., Jones, J. A., Flynn, J. M., Maddocks, K., Rogers, K., Jaglowski, S., Andritsos, L. A., Awan, F. T., Blum, K. A., Grever, M. R., Lozanski, G., Johnson, A. J., \& Byrd, J. C. (2017). BTK(C481S)-mediated 
resistance to ibrutinib in chronic lymphocytic leukemia. Journal of Clinical Oncology, 35, 1437-1443.

113. Byrd, J. C., Smith, S., Wagner-Johnston, N., Sharman, J., Chen, A. I., Advani, R., Augustson, B., Marlton, P., Renee Commerford, S., Okrah, K., Liu, L., Murray, E., Penuel, E., Ward, A. F., \& Flinn, I. W. (2018). First-in-human phase 1 study of the BTK inhibitor GDC-0853 in relapsed or refractory B-cell NHL and CLL. Oncotarget, 9, 13023-13035.

114. Byrd, J. C., Wierda, W. G., Schuh, A., Devereux, S., Chaves, J. M., Brown, J. R., Hillmen, P., Martin, P., Awan, F. T., Stephens, D. M., Ghia, P., Barrientos, J., Pagel, J. M., Woyach, J. A., Burke, K., Covey, T., Gulrajani, M., Hamdy, A., Izumi, R., Frigault, M. M., Patel, P., Rothbaum, W., Wang, M. H., O'Brien, S., \& Furman, R. R. (2020). Acalabrutinib monotherapy in patients with relapsed/refractory chronic lymphocytic leukemia: Updated phase 2 results. Blood, 135(15), 1204-1213.

115. Zhang, T., Inesta-Vaquera, F., Niepel, M., Zhang, J., Ficarro, S. B., Machleidt, T., Xie, T., Marto, J. A., Kim, N., Sim, T., Laughlin, J. D., Park, H., LoGrasso, P. V., Patricelli, M., Nomanbhoy, T. K., Sorger, P. K., Alessi, D. R., \& Gray, N. S. (2012). Discovery of potent and selective covalent inhibitors of JNK. Chemistry \& Biology, 19, 140-154.

116. Ward, R. A., Colclough, N., Challinor, M., Debreczeni, J. E., Eckersley, K., Fairley, G., Feron, L., Flemington, V., Graham, M. A., Greenwood, R., Hopcroft, P., Howard, T. D., James, M., Jones, C. D., Jones, C. R., Renshaw, J., Roberts, K., Snow, L., Tonge, M., \& Yeung, K. (2015). Structure-guided design of highly selective and potent covalent inhibitors of ERK1/2. Journal of Medicinal Chemistry, 58, 4790-4801.

117. Kwiatkowski, N., Zhang, T., Rahl, P. B., Abraham, B. J., Reddy, J., Ficarro, S. B., Dastur, A., Amzallag, A., Ramaswamy, S., Tesar, B., Jenkins, C. E., Hannett, N. M., McMillin, D., Sanda, T., Sim, T., Kim, N. D., Look, T., Mitsiades, C. S., Weng, A. P., Brown, J. R., Benes, C. H., Marto, J. A., Young, R. A., \& Gray, N. S. (2014). Targeting transcription regulation in cancer with a covalent CDK7 inhibitor. Nature, 511, 616-620.

118. Hu, S., Marineau, J. J., Rajagopal, N., Hamman, K. B., Choi, Y. J., Schmidt, D. R., Ke, N., Johannessen, L., Bradley, M. J., Orlando, D. A., Alnemy, S. R., Ren, Y., Ciblat, S., Winter, D. K., Kabro, A., Sprott, K. T., Hodgson, J. G., Fritz, C. C., Carulli, J. P., di Tomaso, E., \& Olson, E. R. (2019). Discovery and characterization of SY-1365, a selective, covalent inhibitor of CDK7. Cancer Research, 79, 3479-3491.

119. Gao, Y., Zhang, T., Terai, H., Ficarro, S. B., Kwiatkowski, N., Hao, M. F., Sharma, B., Christensen, C. L., Chipumuro, E., Wong, K. K., Marto, J. A., Hammerman, P. S., Gray, N. S., \& George, R. E. (2018). Overcoming resistance to the THZ series of covalent transcriptional CDK inhibitors. Cell Chemical Biology, 25, 135-142.e5.

120. Weisner, J., Gontla, R., van der Westhuizen, L., Oeck, S., Ketzer, J., Janning, P., Richters, A., Muhlenberg, T., Fang, Z., Taher, A., Jendrossek, V., Pelly, S. C., Bauer, S., van Otterlo, W. A., \& Rauh, D. (2015). Covalent-allosteric kinase inhibitors. Angewandte Chemie (International Ed. in English), 54, 10313-10316.

121. Weisner, J., Landel, I., Reintjes, C., Uhlenbrock, N., Trajkovic-Arsic, M., Dienstbier, N., Hardick, J., Ladigan, S., Lindemann, M., Smith, S., Quambusch, L., Scheinpflug, R., Depta, L., Gontla, R., Unger, A., Muller, H., Baumann, M., Schultz-Fademrecht, C., Gunther, G., Maghnouj, A., Muller, M. P., Pohl, M., Teschendorf, C., Wolters, H., Viebahn, R., Tannapfel, A., Uhl, W., Hengstler, J. G., Hahn, S. A., Siveke, J. T., \& Rauh, D. (2019). Preclinical efficacy of covalent-allosteric AKT inhibitor borussertib in combination with trametinib in KRAS-mutant pancreatic and colorectal Cancer. Cancer Research, 79, 2367-2378.

122. Park, K., Tan, E. H., O'Byrne, K., Zhang, L., Boyer, M., Mok, T., Hirsh, V., Yang, J. C., Lee, K. H., Lu, S., Shi, Y., Kim, S. W., Laskin, J., Kim, D. W., Arvis, C. D., Kolbeck, K., Laurie, S. A., Tsai, C. M., Shahidi, M., Kim, M., Massey, D., Zazulina, V., \& Paz-Ares, L. (2016). Afatinib versus gefitinib as first-line treatment of patients with EGFR mutation-positive nonsmall-cell lung cancer (LUX-lung 7): A phase 2B, open-label, randomised controlled trial. The Lancet Oncology, 17, 577-589. 
123. Burger, J. A., Barr, P. M., Robak, T., Owen, C., Ghia, P., Tedeschi, A., Bairey, O., Hillmen, P., Coutre, S. E., Devereux, S., Grosicki, S., McCarthy, H., Simpson, D., Offner, F., Moreno, C., Dai, S., Lal, I., Dean, J. P., \& Kipps, T. J. (2020). Long-term efficacy and safety of firstline ibrutinib treatment for patients with CLL/SLL: 5 years of follow-up from the phase 3 RESONATE-2 study. Leukemia, 34(3), 787-798.

124. Liu, R., Yue, Z., Tsai, C. C., \& Shen, J. (2019). Assessing lysine and cysteine reactivities for designing targeted covalent kinase inhibitors. Journal of the American Chemical Society, $141,6553-6560$. 